\title{
Pricing of oral generic cancer medicines in 25 European countries; findings and implications
}

Brian Godman ${ }^{1,2,3,4^{*}}$, Andrew Hill ${ }^{5}$, Steven Simoens ${ }^{6}$, Amanj Kurdi ${ }^{1}$, Jolanta Gulbinovič ${ }^{7}$, Antony P Martin ${ }^{2,8}$, Angela Timoney ${ }^{1,9}$, Dzintars Gotham ${ }^{10}$, Janet Wale ${ }^{11}$, Tomasz Bochenek ${ }^{12}$, Celia Rothe ${ }^{12}$, Iris Hoxha ${ }^{13}$, Admir Malaj ${ }^{14}$, Christian Hierländer ${ }^{15}$, Robert Sauermann ${ }^{15}$, Wouter Hamelinck ${ }^{16}$, Zornitza Mitkova ${ }^{17}$, Guenka Petrova ${ }^{17}$, Ott Laius ${ }^{18}$, Catherine Sermet ${ }^{19}$, Irene Langer ${ }^{20}$, Gisbert Selke ${ }^{20}$, John Yfantopoulos ${ }^{21}$, Roberta Joppi²2, Arianit Jakupi ${ }^{23}$, Elita Poplavska ${ }^{24}$, leva GreiciuteKuprijanov ${ }^{25}$, Patricia Vella Bonanno ${ }^{1}$, JF (Hans) Piepenbrink ${ }^{26}$, Vincent de Valk ${ }^{26}$, Carolin Hagen ${ }^{27}$, Anne Marthe Ringerud ${ }^{27}$, Robert Plisko ${ }^{28}$, Magdalene Wladysiuk ${ }^{28}$, Vanda Marković-Peković ${ }^{29,30}$, Nataša Grubiša ${ }^{31}$, Tatjana Ponorac ${ }^{32}$, Ileana Mardare ${ }^{33}$, Tanja Novakovic ${ }^{34}$, Mark Parker ${ }^{34}$, Jurij Fürst $^{35}$, Dominic Tomek ${ }^{36}$, Mercè Obach Cortadellas ${ }^{37}$, Corrine Zara ${ }^{37}$, Maria Juhasz-Haverinen ${ }^{38}$, Peter Skiold ${ }^{39}$, Stuart McTaggart ${ }^{40}$, Alan Haycox ${ }^{1}$

${ }^{1}$ Strathclyde Institute of Pharmacy and Biomedical Sciences, University of Strathclyde, Glasgow G4 ORE, United Kingdom. Email: Brian.godman@strath.ac.uk; amanj.baker@strath.ac.uk; patricia.vellabonanno@strath.ac.uk

${ }^{2}$ Health Economics Centre, University of Liverpool Management School, Liverpool, UK. Email: Brian.Godman@liverpool.ac.uk; a.p.martin@liverpool.ac.uk; a.r.haycox@liverpool.ac.uk ${ }^{3}$ Division of Clinical Pharmacology, Karolinska Institute, Karolinska University Hospital Huddinge, SE141 86, Stockholm, Sweden. Email: Brian.Godman@ki.se.

${ }^{4}$ School of Pharmaceutical Sciences, Universiti Sains Malaysia, Penang, Malaysia

${ }^{5}$ Institute of Translational Medicine, University of Liverpool, UK. Email: microhaart@aol.com

${ }^{6} \mathrm{KU}$ Leuven Department of Pharmaceutical and Pharmacological Sciences, Leuven, Belgium. Email: steven.simoens@kuleuven.be

7Department of Pathology, Forensic Medicine and Pharmacology, Institute of Biomedical Sciences, Faculty of Medicine, Vilnius University, Vilnius, Lithuania. Email: jolanta.gulbinovic@gmail.com ${ }^{8}$ HCD Economics, The Innovation Centre, Daresbury, WA4 4FS, UK. Email:

antony.martin@hcdeconomics.com

${ }^{9}$ NHS Lothian, Edinburgh, UK. Email: angela.timoney@nhs.net

${ }^{10}$ Independent researcher, Boston, MA, United States. Email: dzintarsgotham@gmail.com

${ }^{11}$ Independent consumer advocate, 11a Lydia Street, Brunswick, Victoria 3056 Australia. Email: socrates111@bigpond.com

${ }^{12}$ Department of Drug Management, Faculty of Health Sciences, Jagiellonian University Medical College, Krakow, Poland. Email: mxbochen@cyf-kr.edu.pl; celia.rothe@outlook.de

${ }^{13}$ Department of Pharmacy, Faculty of Medicine, University of Medicine, Tirana, Albania. Email: iris.hoxha@umed.edu.al

${ }^{14}$ University of Medicine, Tirana, Albania. Email:admir.malaj@yahoo.it

15Hauptverband der Österreichischen Sozialversicherungsträger, Haidingergasse 1, AT-1030, Vienna, Austria. Email: christian.hierlaender@sozialversicherung.at;

Robert.Sauermann@sozialversicherung.at

${ }^{16}$ Statistics Department, APB,Rue Archimède 11, 1000 Bruxelles, Belgium. Email:

wouter.hamelinck@apb.be

${ }^{17}$ Faculty of Pharmacy, Department of Social Pharmacy and Pharmacoeconomics, Medical University of Sofia, Sofia, Bulgaria. Email: guenka.petrova@gmail.com; sppmitkova@mail.bg

18State Agency of Medicines, Nooruse 1, 50411 Tartu, Estonia. Email: Ott.Laius@ravimiamet.ee

19IRDES, 117 bis rue Manin, 75019 Paris, France. Email: sermet@irdes.fr

20Wissenschaftliches Institut der AOK (WidO), Rosenthaler Straße 31, 10178 Berlin, Germany. Email:

Gisbert.Selke@wido.bv.aok.de; irene.langner@wido.bv.aok.de

${ }^{21}$ School of Economics and Political Science, University of Athens, Athens. Email:

yfantopoulos@gmail.com

22Pharmaceutical Drug Department, Azienda Sanitaria Locale of Verona, Verona, Italy;

Email: roberta.joppi@ulss20.verona.it

${ }^{23}$ A2 - Pharmaceutical Consulting, Prishtina, Kosovo. Email: arianit.jakupi@rks-gov.net; arianiti@gmail.com

${ }^{24}$ Institute of Public Health \& Department of Dosage Form Technology, Faculty of Pharmacy, Riga

Stradins University, Latvia. Email: elita.poplavska@rsu.Iv

${ }^{25}$ Department of Pharmacy, Ministry of Health of the Republic of Lithuania, Vilnius, Lithuania, Email: leva.Greiciute-Kuprijanov@sam.It

${ }^{26}$ National Health Care Institute (ZIN), Eekholt 4, NL-1112 XH Diemen, Netherlands. Email:

VValk@zinl.nl; HPiepenbrink@zinl.nl 
${ }^{27} \mathrm{HTA}$ and Reimbursement, Norwegian Medicines Agency, Oslo, Norway. Email:

Carolin.Hagen@legemiddelverket.no; anne.ringerud@legemiddelverket.no

${ }^{28} \mathrm{HTA}$ Consulting, Starowiślna Str. 17/3, 31-038 Cracow, Poland. Email: m.wladysiuk@hta.pl; r.plisko@hta.pl

${ }^{29}$ Ministry of Health and Social Welfare, Banja Luka, Republic of Srpska, Bosnia and Herzegovina

30University of Banja Luka, Faculty of Medicine, Department of Social Pharmacy, Banja Luka,

Republic of Srpska, Bosnia and Herzegovina. Email: vanda.markovic-pekovic@med.unibl.org

${ }^{31}$ Health Insurance Fund of Republika Srpska, Zdrave Korde 8, 78000 Banja Luka, Republic of

Srpska, Bosnia and Herzegovina. Email: natasa.grubisa@zdravstvo-srpske.org

${ }^{32} \mathrm{Agency}$ for medicines and medical devices of Bosnia and Herzegovina, Veljka Mladjenovica bb,

78000 Banja Luka, Bosnia and Herzegovina. Email: t.ponorac@almbih.gov.ba

${ }^{33}$ Faculty of Medicine, Public Health and Management Department, "Carol Davila" University of

Medicine and Pharmacy Bucharest, 050463 Bucharest, Romania. Email: ileana.mardare@umfcd.ro

34ZEM Solutions, Mosorska 9, 11000 Belgrade, Serbia. Emails:tanja@zem-solutions.com;

mark@zem-solutions.com

${ }^{35}$ Health Insurance Institute, Miklosiceva 24, SI-1507 Ljubljana, Slovenia. Email: Jurij.Furst@zzzs.si

${ }^{36}$ Faculty of Medicine, Slovak Medical University in Bratislava, Bratislava, Slovakia. Email:

tdmia@slovanet.sk

${ }^{37}$ Barcelona Health Region, Catalan Health Service, Esteve Terrades 30, 08023 Barcelona, Spain.

Email: czara@catsalut.cat; mobach@catsalut.cat

${ }^{38}$ Stockholm County Council, Stockholm, Sweden. Email: maria.juhasz-haverinen@sll.se

${ }^{39}$ TLV (Dental and Pharmaceutical Benefits Agency), Fleminggatan 18, 104 22, Stockholm, Sweden.

Email: Peter.Skiold@tlv.se

${ }^{40} \mathrm{NHS}$ National Services Scotland, Gyle Square, 1 South Gyle Crescent, Edinburgh, UK. Email:

stuart.mctaggart@nhs.net

*Author for correspondence: Strathclyde Institute of Pharmacy and Biomedical Sciences, University of Strathclyde, Glasgow G4 ORE, United Kingdom. Email: Brian.godman@strath.ac.uk. Telephone: 0141548 3825. Fax: 01415522562 and Division of Clinical Pharmacology, Karolinska Institute, Karolinska University Hospital Huddinge, SE-141 86, Stockholm, Sweden. Email:

Brian.Godman@ki.se. Telephone + 468 58581068. Fax + 46859581070

(Accepted for publication GABI Journal - please keep CONFIDENTIAL)

\section{Abstract}

Introduction: There are appreciable concerns among European health authorities with growing expenditure on cancer medicines and issues of sustainability. The enhanced use of low cost generics could help. Aims: Consequently, there is a need to comprehensively document current and future arrangements regarding the pricing of generic cancer medicines across Europe, and whether these are indication specific, as well as how this translates into actual prices to provide future direction. Methodology: Mixed method approach with qualitative research among senior health authority personnel and their advisers. Quantitative research via health authority databases to ascertain current prices for oral cancer medicines that had lost their patent and the influence of population size and economics on prices. Results: 25 European countries participated. Currently we see (a) variable approaches to the pricing of generic cancer medicines, which will continue; (b) no concerns with substitution for oral generic cancer medicines; (c) substantial price reductions versus originators for generic capecitabine (up to $-93.1 \%$ ), generic imatinib (up to $-97.8 \%$ ) and generic temozolomide (up to $-80.7 \%$ ). Prices for oncology medicines are not indication specific, and are not affected by population size although influenced by pricing approaches. There have also been price increases for some nonpatented cancer medicines following manufacturer changes although now stabilising. Conclusion: The considerable price reductions seen for some generics means health authorities should further encourage the use of generic oncology medicines when they become available to fund increased volumes and new valued cancer medicines. Countries are also starting to address price increases for generics following changes in the manufacturer

Key words: Cancer, pricing, generics, generic regulations, Europe, Health Policy 


\section{Introduction}

Despite the limited health gain for most new cancer medicines, their prices have increased appreciably in recent years (1-7). This is reflected in the price per life year gained for new cancer medicines rising four fold during the past twenty years after adjusting for inflation $(2,8)$. Typically, prices for new cancer medicines are now approximately $€ 6000$ - $€ 9000 /$ patient/ month and growing $(1,5,9)$, with typically higher prices for new cancer medicines in the USA versus Europe. As a result of rising prices for new cancer medicines, as well as increased prices for patented cancer medicines $(5,10-12)$, coupled with the increasing prevalence of cancer $(1,13)$, spending on cancer medicines in Europe has more than doubled in recent years, rising from €8billion in 2005 to $€ 19$.1billion in 2014 (at current prices) (14).

As a result, medicines for oncology now dominate pharmaceutical expenditures in developed markets, with projected world-wide sales for oncology medicines in 2017 ranging from US $\$ 74$ to US $\$ 84$ billion (15). Overall, total world-wide sales of oncology medicines are expected to reach US $\$ 112$ billion (€91 billion) per year by 2020 (16). Further growth is expected after this with cases of cancer worldwide likely to rise to 21.4 million per year by $2030(1,13)$ coupled more with than 500 companies actively pursuing new oncology medicines in over 600 indications, and looking to benefit from their investment (17). The cost of cancer care also currently accounts for up to $30 \%$ of total hospital expenditure across diseases among European countries, and this is also rising with the launch of new premium priced cancer medicines $(14,18)$.

Increasing prices for new cancer medicines, combined with increasing prevalence rates, is putting considerable strain on patients to access cancer treatments and healthcare systems to fund them (1923). High reimbursed prices for new cancer medicines certainly in Europe have been enhanced by the emotive nature of cancer, capturing public, physician, and political attention $(13,24-27)$. If these trends with new cancer medicines continue, there is a real risk that universal healthcare across Europe will become unsustainable, which will not be in the best interest of any key stakeholder group. Initiatives among European health authorities to help fund future cancer treatments, including new valued high cost medicines, include encouraging greater use of generic cancer medicines when they become available $(12,26)$. This is especially important given the increasing number of cancer medicines that are now out of patent (28). Initiatives to enhance greater use of generic cancer medicines include encouraging international non-proprietary name (INN) prescribing, financial incentives to enhance the prescribing and dispensing of generics versus originators, as well as compulsory generic substitution (29-38). INN prescribing is supported by multiple publications showing no difference in effectiveness and safety between generics and originators across a range of disease areas including oncology medicines $(28,39-44)$. There have though been concerns with generic imatinib due to different polymorphic forms between the originator and generics as early small scale studies suggested differences (45). However later studies involving more patients showed no difference in outcomes between generics and originators of imatinib $(45,46)$, and, typically, no substantial evidence that generic imatinib is less effective than the originator (47).

In general, prices for generic medicines in Europe are $20 \%$ to $80 \%$ below originator prices; however, some generics can be priced as low as $2 \%$ to $4 \%$ of the originator price before the patent was lost $(48,49)$. As a result, substantial differences can occur in the prices of generics across Europe $(37,50$, 51). Overall, low prices can potentially be achieved for generic cancer medicines because of the low cost of goods that have been reported at just $1 \%$ or more of originator prices for some new cancer medicines $(52,53)$. These low cost of goods have already resulted in considerable discounts for generic imatinib across countries versus pre-patent loss prices $(54,55)$. However, this is not universal. For instance in China, generic imatinib is only $10-20 \%$ below originator prices although generic capecitabine is $50 \%$ lower than originator prices (56). There have also been low prices for generic versions of paclitaxel in Europe at just over $1 \%$ of originator prices (57). Docetaxel also has a low price in some European markets enhanced by an appreciable number of generic versions available (26). Having said this, changes in the manufacturer have resulted in the prices of some low volume old anti-cancer medicines rising appreciably among European countries including Italy and the UK (58). However, pharmaceutical companies are now being fined for such behaviour, e.g. $€ 5.2 \mathrm{million}$ for Aspen in Italy for price increases for some of its anti-cancer medicines, with ongoing investigations and initiatives across Europe to address this $(59,60)$. 
In some European countries, there have also been issues regarding the prescribing of certain generic medicines where there are different indications, one of which is still patent protected. This was the case with pregabalin for the treatment of neuropathic pain as opposed to epilepsy (61).

There have also been concerns with drug shortages if the prices of medicines including generics become too low, which is already happening for certain parenteral medicines (62). However, these concerns have to be balanced against the increasing availability and use of low cost generic medicines to release resources to fund increased cancer care including new innovative medicines, reducing patient co-payments where these exist, and stimulating innovation $(13,48,63-65)$.

Consequently, there is a need to document current regulations surrounding the pricing of generic oral anti-cancer medicines across Europe, and their impact on subsequent prices, as well as issues regarding prices of medicines once one indication loses its patent but not the others. As a result, the aims of this paper are multiple. The primary aim is to document current arrangements for the pricing of oral generic medicines across Europe and whether there are any differences in pricing policies for generic cancer medicines versus those for other disease areas. This is important to maximise savings following generic availability as we do see differences in reimbursement decisions for new medicines for cancer versus those for other disease areas $(27,66)$. Secondly, to investigate what happens to the prices of oral cancer medicines if one indication loses its patent but not the other indication(s) since indication-specific pricing will undoubtedly reduce potential savings following generic availability, and, as mentioned, there were issues with the prescribing of pregabalin across indications when the first indication lost its patent (61). Thirdly, to investigate how payers and their advisers envisage developments in the pricing of oral generic medicines for cancer as more cancer medicines lose their patents. Fourthly, to assess whether health authorities have any concerns with patient safety when prescribing oral generic cancer medicines similar to the situation with medicines with a narrow therapeutic index such as lithium and certain medicines for epilepsy (67-69). Fifthly, to review current prices for a number of oral cancer medicines across Europe where generic versions are available in all or some of the countries. This will also include an evaluation of prices over time to fully assess the impact of the different pricing arrangements for generic cancer medicines across Europe since we are aware that prices of generics can vary substantially across Europe due to different policies $(26,37$, 48, 49), and that Central and Eastern European (CEE) countries are likely to have generics earlier (70). Sixthly, to assess whether there are any differences in the prices of generics by population size and geography (CEE vs. Western European countries) as there have been concerns that countries with small populations, and hence lower economies of scale, may have difficulty negotiating low prices for medicines (71); however, published literature has not found to be the case $(31,72)$. Countries with greater economic power may potentially be able to negotiate lower prices for generics, and we will also investigate this. Lastly, as mentioned, prices of some old low volume anti-cancer medicines have risen among European countries in recent years with changes in the manufacturer (58), and we will assess the impact of any changes in manufacturers on subsequent prices, and the likely future direction.

We developed a number of hypotheses for the different aims. These include:

- there will be no difference in the pricing of generics for cancer medicines versus generics for other disease areas and no changes in the short term with pricing regulations for generics

- there may be differences in the prices of cancer medicines for different indications similar to pregabalin

- there will be no safety concerns with oral generic cancer medicines and so no concerns with substitution

- there will be substantial price reductions for oral generic cancer medicines similar to other generic medicines; however, prices will vary considerably across Europe similar to other generics

- population size and economic power will make limited difference on possible prices for generics, with prices mainly governed by the pricing policies in individual countries.

We believe that this is the first time that such comprehensive research regarding the regulations surrounding the pricing of oral cancer medicines, and their influence on subsequent prices, has been undertaken across Europe. Consequently, we believe the findings will inform future discussions within and between European and other countries regarding the pricing of oral generic cancer medicines now and into the future. In addition, we aim to stimulate discussions regarding subsequent prices and/ or discounts for still patented oral cancer medicines that used off-patented products as their 
comparator during pricing negotiations. As a result, help with issues of affordability and sustainability of medicine use in the future in this high priority disease area.

When we refer to 'generics', we mean the chemical entity (INN). This study also includes imatinib, a comparatively newer anti cancer agent, which is treated similarly to other oral generic cancer medicines. Biosimilars of originator biological medicines are regulated by a different framework, and incentives to increase their use are different (73). Consequently, we will not be discussing biosimilars.

We have chosen to concentrate on Europe in view of the high use of generic medicines in this region. There are also different approaches to the pricing of generics among the various countries, as well as an appreciable number of existing initiatives to enhance the prescribing of generic medicines.

\section{Methodology}

A mixed method approach was employed including both qualitative and quantitative research to meet the study objectives, and included 25 European countries (Box 1).

\section{Box 1 - European countries taking part in the study}

Albania, Austria, Belgium, Bosnia \& Herzegovina (Republic of Srpska), Bulgaria, Cyprus Estonia, France, Germany, Greece, Italy, Kosovo, Latvia, Lithuania, Malta, Netherlands, Norway, Poland, Romania, Serbia, Slovenia, Slovakia, Spain (represented by pricing data from Catalonia), Sweden, and the UK (represented by pricing data from Scotland with tariff prices consistent across the UK).

This appreciable number of European countries fully encompasses differences in geography, population size, gross domestic product (GDP) per capita, pricing approaches towards generics as well as different approaches to the financing of healthcare $(30,70,74)$. Countries were also broken down into CEE and Western European countries based on the OECD definition (75) to ascertain any differences in the pricing of oral generic cancer medicines based on population sizes and market power.

Qualitative interviews were undertaken with senior personnel within health authorities including heads of pricing and reimbursement of medicines as well as their advisers and a limited number of academics with expertise on national pharmaceutical issues and other key issues across European countries. The involvement of these senior level personnel in the qualitative interviews, and their involvement as co-authors, is seen as very important to enhance the accuracy, robustness and insight of the replies as there have been concerns when such approaches are not used $(76,77)$. The coauthors were either identified via the Piperska group $(78,79)$ - a multidisciplinary network of professionals with interest in the quality use of medicines - or had been previous co-authors on similar pan-European projects involving generic medicinal products $(29,80-82)$. We have successfully used this approach in other key areas $(30,61,70,73,74,80,81,83)$.

The qualitative questions to address the identified objectives included:

- Current regulations for the pricing of generics in their country and whether there are any differences for oral generic cancer medicines versus those for other disease areas

- Whether there are any concerns with the substitution of any of the selected oral cancer medicines or other oral cancer medicines similar to the situation with lithium and some medicines for epilepsy?

- What is the current situation for the pricing of multiple sourced medicines for cancer if one or more indications are still patent protected building on the experiences with pregabalin?

- Any likely future changes in the pricing of oral generic medicines for patients with cancer?

If applicable, pricing policies for generics were broken down into three principal groups to aid comparisons. This builds on previous publications that have used this approach (84-87), and include:

- prescriptive pricing policies (price regulated market) with established percentage reductions for successive generics

- market forces (free market) where there is typically free pricing for generics with market forces helping to drive down prices 
- mixed approach (combination) including prescriptive approaches, market forces and other mechanisms including external reference pricing among selected European countries as external reference pricing is common across Europe

Health authority and health insurance company databases were used for the quantitative research apart from Greece and Serbia where commercial sources were used. The information within these databases is robust as they are typically used to trigger payment to pharmacists. In addition, the databases are regularly audited, and cover the whole country rather than a sample of pharmacies as seen with commercial databases. We have used this approach before when conducting research on prices and utilisation of generics, originators and patented products within a class or related class $(30$, $49,70,72,80-82,88)$.

The oral cancer medicines selected for the quantitative research were busulfan (L01AB01), capecitabine (L01BC06), chlorambucil (L01AA02), cyclophosphamide (L01AA01), flutamide (L02BB01), imatinib (L01XE01), melphalan (L01AA03), methotrexate (L01BA01), and temozolomide (L01AX03) (89). These oral cancer medicines were chosen to provide a range of medicines for use across different cancer types, with typically multiple indications, covering the oral cancer medicines listed in the World Health Organisation (WHO) essential medicines list, and exhibiting varying timings regarding the loss of patent, building on previous publications (55). Oral medicines such as gefitinib, sorafenib, sunitinib and tioguanine were not included as there appeared to be no generics yet available for these oral cancer medicines even among the selected CEE countries at the time of the study. The (non-) tyrosine kinase inhibitors are a particular case as there are typically multiple indications as well as potentially different dates for patent loss across countries (90).

Since the perspective of this study is that of health authorities, reimbursed prices were principally chosen for comparative purposes rather than total prices, which include patient co-payments. Reimbursed prices can include prices after deducting legally mandated discounts; however, this is unlikely for generic medicines. In a minority of countries, e.g. Kosovo, procured and total prices were used as reimbursed prices were unavailable. In Italy and Norway, reimbursed prices were also listed but the medicines are typically dispensed in hospitals where further confidential discounts are provided. However, since these discounts are confidential, we could only report ambulatory care prices. Furthermore, in some countries, prices did not include VAT and/ or pharmacy margins, e.g. Malta, the Netherlands and the Republic of Srpska. However, this was not seen to have an appreciable impact on the analyses since percentage reductions were typically used for comparative purposes to assess the influence of different policies. In addition, the prices of generics at least initially in a number of European countries are based on percentage reductions from pre-patent loss originator prices $(30,70)$. We have successful used this approach in a number of previous publications $(30,70,74,80,84)$.

We are conscious that we used prices from Scotland rather than the UK as a whole. However, there are no differences in prices across the UK with reimbursed prices in ambulatory care based on the tariff price coupled with free market competition, which leads to further price reductions over time. Similarly, no differences are envisaged in generic and originator prices in ambulatory care in Catalonia versus Spain as a whole. However, we acknowledge that there will be differences in hospital prices across Spain through variations in discounts and managed entry agreements between the different regions (91).

Prices were collected over a period of time between 2013 and 2017, based on the unit, e.g. tablet strength, for the different originators and the cheapest generic substitute unit available, especially for branded generics, as opposed to defined daily doses (DDDs). Unit strength was chosen as generally there are no DDDs for oral cancer medicines in view of typically a number of indications for each molecule (89). The documented prices for each year between 2013 and 2017 were the last available price for that year, e.g. October to December if prices are adjusted every 3 months or December if prices are adjusted monthly. The years were chosen to assess the extent of any price changes in recent years especially given recent price increases for some off-patent medicines.

The actual unit strength chosen for comparative purposes reflects the most used strength in a number of European countries, although we recognise that there may be different strengths available in some countries. In addition:

- If no generic was available in a country, this was recorded as NA (not available) 
- If the generics were not available in the suggested strength - but were available in different strengths along with the originator - then the strengths were typically recorded to track particular generic prices over time and in relation to the originator. This may mean we could not undertake comparisons between countries in all cases; however, this was a secondary consideration

- If there were different pack sizes for the generics versus originators in the stated strength, the pack size chosen was the size that gave the lowest price per unit during the year and again a note was made of this practice

- If the generics were only available in liquid form but the originator was still available as a tablet, we stated that the generic was not available as a tablet (NA) and just recorded the originator details in the spreadsheet. However, the strength of the generic liquid formulation and its price over time were recorded separately on an MS Excel sheet to see if this changed over time. This would be commented on if pertinent

Initially prices were documented in the country's currency if this was not Euros. Subsequently where relevant, prices were converted to Euros for the purposes of comparison based on current exchange rates and validated with the co-authors to enhance the robustness of the findings (Table 1A).

Table 2A in the appendix contains details of the population sizes and the breakdown of countries into three groups for analysis purposes (small, medium and large). Countries with populations under three million were described as small, those with populations between 3 and 16 million as medium, and the remainder as large to produce three roughly equal groups although recognising that more countries were in the 'small' category than in the others.

Statistical tests were performed to ascertain any trends in prices across countries as well as any difference in price reductions over time as a result of the different approaches towards the pricing of generics across Europe. The significance threshold was set at $p>0.05$. Statistical tests were also run to check whether prices were influenced by population size as this has been a concern in the past. However, we did not have enough variables to perform any multivariate analyses as there are not enough specific measures in each European country that had been initiated to control the price of generic cancer medicines which could be used as a yes/ no variable. We have though collated the impact of the different pricing approaches for generic medicines across Europe as one of the principal objectives of this paper was to document these and their influence on subsequent prices for oral generic cancer medicines.

No analysis was made regarding the impact of volumes on generic prices as seen in other studies because this was not a focus of the paper (92). This will be followed up in future studies. Potential savings from the increased utilisation of generic medicines for cancer over time will also form a separate project building on previous calculations (93).

\section{Results}

In line with the objectives of this paper, we will first report the findings from the qualitative research. This will be followed by the findings from the quantitative research.

\subsection{Regulations surrounding the pricing of generics including those for cancer across Europe}

\subsubsection{Regulations for the pricing of generics generally and for oral cancer medicines including likely changes in the short term}

As previously seen, there were differences in the approaches to the pricing of generics among the various European countries (Table 1), which could again be categorised under three broad headings. These are: (i) prescriptive pricing approaches; (ii) market forces and (iii) and a mixture of the approaches.

As shown in Table 1, there were no differences in the pricing approaches for generic oral medicines for oncology compared with those for other disease areas (Table 1) apart from the fact that in some countries these cancer medicines were dispensed in hospitals, which could include additional discounts that are typically confidential. This is important given the considerable savings that can be achieved with the introduction of generics (Table 3). 
Table 1 - Current pricing arrangements for generics for each country including those for cancer (starting with countries with the lowest populations), with pricing approaches categorised under three headings

\begin{tabular}{|c|c|}
\hline $\begin{array}{l}\text { Country and } \\
\text { category of } \\
\text { pricing } \\
\text { approaches }\end{array}$ & Current and future situation \\
\hline $\begin{array}{l}\text { Malta (94) } \\
\text { (Mixed) }\end{array}$ & $\begin{array}{l}\text { Malta uses an external reference price system with other European countries for new } \\
\text { products and comparison to previous tendering prices to set a maximum price to be } \\
\text { awarded for tenders for publicly procured medicines. Procurement is undertaken } \\
\text { through a centralised tendering system which covers all medicines listed on the } \\
\text { Formulary of the Government Health Services for all entitled patients in primary as well } \\
\text { as secondary and tertiary care. Medicinal products are listed on the Formulary by INN } \\
\text { and tendering specifications are by INN. } \\
\text { The principal objective is to give all entitled patients access to all medicines listed on } \\
\text { the Formulary. Patients do not pay for medicines at the point of dispensing. } \\
\text { These regulations apply equally to generics for cancer as well as non-cancer } \\
\text { indications. } \\
\text { Typically, prices apply to the medicinal product rather than the indication. } \\
\text { No changes are envisaged to the pricing of oral generic cancer medicines in the short } \\
\text { to medium term }\end{array}$ \\
\hline $\begin{array}{l}\text { Republic of } \\
\text { Srpska (Bosnia \& } \\
\text { Herzegovina) (29, } \\
72,95) \text { (mixed) }\end{array}$ & $\begin{array}{l}\text { A Rulebook on the method of price control, the method of forming prices of medicinal } \\
\text { products, and the method of reporting on medicinal products prices in Bosnia and } \\
\text { Herzegovina (Official Gazzette of B\&H No 3:2017), was adopted by the Council of } \\
\text { Ministers of B\&H on the basis of the provision set in the Law on Medicinal Products } \\
\text { and Medicinal Devices of B\&H. } \\
\text { This Rulebook defines the maximum wholesale price of the medicine in B\&H (VAT not } \\
\text { included) and includes a reference pricing system. It is applied both to generics and } \\
\text { inovative medicines on the same way. For generics, prices are compared with the } \\
\text { pricies of currently available generics. For inovative medicines, prices are compared to } \\
\text { other inovative medicines. This refers to all medicines with marketing authorisation } \\
\text { issued by the Agency for Medicinal Products and Medical Devices of B\&H (Agency) } \\
\text { and dispensed via a medical prescription. The responsible institution for the calculation } \\
\text { of the prices defined by this Rulebook is the Agency. VAT in B\&H (all goods) is } 17 \% \text {. } \\
\text { Medicines for in-hospital use such as typically those for cancer are procured by the } \\
\text { Health Insurance Fund of the Republic of Srpska via Public Procurement Law of B\&H } \\
\text { (Official Gazzette of B\&H, No } 39: 2014 \text { ). Medicines are procured via tender procedures, } \\
\text { with established criteria for awarding the contract. A decision is subsequently made on } \\
\text { the most favorable bidder (the bidders are wholesalers). } \\
\text { Medicines used in the treatment of cancer in the Republic are procured by the Health } \\
\text { Insurance Fund of the Republic of Srpska for hospitals and listed with defined } \\
\text { indications for use. The price will apply to all listed indications whether some are patent } \\
\text { protected or not. } \\
\text { No changes are envisaged to the pricing of oral generic cancer medicines in the short } \\
\text { to medium term }\end{array}$ \\
\hline $\begin{array}{l}\text { Cyprus (market } \\
\text { forces - generics } \\
\text { public sector) }\end{array}$ & $\begin{array}{l}\text { Generics are priced up to the } 80 \% \text { of branded product's price, which are priced via } \\
\text { external price referencing. This price is applicable for the private sector. The public } \\
\text { sector procures all medicines with tenders, which can lead to low prices. Medicines for } \\
\text { cancer (and other conditions where prices are high) are covered for the whole } \\
\text { population by the public sector. Consequently, there is little or no private market for } \\
\text { medicines for cancer in reality. } \\
\text { There are no differences in the pricing of generics for medicines for cancer than other } \\
\text { conditions in the public sector, and no concerns with substitution of current generic } \\
\text { medicines. }\end{array}$ \\
\hline
\end{tabular}




\begin{tabular}{|c|c|}
\hline & $\begin{array}{l}\text { If an indication of a branded product is patented, this does not affect the pricing of the } \\
\text { generics for the other indications. The branded product is priced the same for all the } \\
\text { indications/uses irrespective of the patent status of each indication and the availability } \\
\text { of generic alternatives for the remaining indications. } \\
\text { Once the National Health System is in place in Cyprus (June } 2019 \text {-outpatient \& } 2020 \\
\text { full NHS), medicines will typically be reimbursed by the national health insurance } \\
\text { organisation (HIO) and will be subject to rebates and clawbacks based on the list } \\
\text { price. Pricing will continue to be performed by the MoH, with several changes being } \\
\text { considered which will affect list prices. }\end{array}$ \\
\hline $\begin{array}{l}\text { Estonia (96) } \\
\text { (mixed) }\end{array}$ & $\begin{array}{l}\text { The first generic entering the market has to be } 30 \% \text { cheaper than the originator and the } \\
\text { following generic(s) must be } 10 \% \text { cheaper than the current highest priced generic to be } \\
\text { reimbursed. } \\
\text { These regulations apply to all generic medicines whether for oncology or not. } \\
\text { The generics are provided the same terms for prescribing as the originator regarding } \\
\text { the indications and any possible restrictions. } \\
\text { No changes are envisaged to the pricing of oral generic cancer medicines in the short } \\
\text { to medium term. }\end{array}$ \\
\hline $\begin{array}{l}\text { Kosovo (22) } \\
\text { (process of being } \\
\text { established) }\end{array}$ & $\begin{array}{l}\text { Currently medicines are procured by the central pharmacy at the Ministry of Health and } \\
\text { distributed to all cancer clinics. The Ministry of Health is currently drafting } \\
\text { administrative instructions regarding future pricing and reimbursement considerations } \\
\text { for Kosovo. } \\
\text { There is no difference between the system for medicines for cancer as opposed to } \\
\text { other disease areas. } \\
\text { The procured generic medicines can be used for all pertinent indications whether some } \\
\text { are patent protected or not. } \\
\text { Likely to see external referencing pricing in the future as well as greater scrutiny } \\
\text { regarding the prescribing of cancer medicines against agreed guidance given current } \\
\text { concerns. }\end{array}$ \\
\hline $\begin{array}{l}\text { Latvia (96) } \\
\text { (mixed) }\end{array}$ & $\begin{array}{l}\text { The price of the first generic entering the reimbursement list should be at least } 30 \% \\
\text { lower than the originator price. The price of the following two generics should be at } \\
\text { least } 10 \% \text { less than the current list price. All the subsequent generics should be priced } \\
\text { at least } 5 \% \text { less than the current list price of the reference group for reimbursement. In } \\
\text { addition, the price of generics should not exceed the prices in Estonia and Lithuania, } \\
\text { and the third lowest price in Czech Republic, Romania, Slovakia, Hungary, and } \\
\text { Denmark, with all medicines with the same indication reimbursed at the same rate. } \\
\text { These regulations apply to all generics whether for cancer indications or not. } \\
\text { The reimbursement system lists by INN with respective to given conditions and does } \\
\text { not distinguish patented and not patented indications. } \\
\text { The national strategy for improving oncology care } 2017 \text { - } 2020 \text { published in } 2016 \text { does } \\
\text { not include any new provisions regarding the pricing of oral generic medicines in } \\
\text { Latvia. }\end{array}$ \\
\hline Slovenia (mixed) & $\begin{array}{l}\text { The National Agency sets the highest allowable prices for generics based on the } \\
\text { average price in } 3 \text { reference countries: France, Germany Austria. The Health Insurance } \\
\text { Institute (ZZZS) can negotiate lower prices. } \\
\text { For the originator and all generics, the therapeutic group (cluster) is established with } \\
\text { ZZZS covering } 100 \% \text { the costs of the generic medicine with the lowest price across } \\
\text { indications. If the originator is more expensive, the patient pays the difference. } \\
\text { However, physicians can protect a patient from co-payment with a "Do not substitute" } \\
\text { clause on prescription. } \\
\text { These regulations apply to generics for cancer as well as non-cancer indications. }\end{array}$ \\
\hline
\end{tabular}




\begin{tabular}{|c|c|}
\hline & $\begin{array}{l}\text { There are no envisaged changes to the pricing of generics in Slovenia; however, the } \\
\text { system should be improved to enhance INN prescribing including biosimilars }\end{array}$ \\
\hline $\begin{array}{l}\text { Lithuania }(87,97) \\
\text { (mixed) }\end{array}$ & $\begin{array}{l}\text { The first generic medicine must be at least } 50 \% \text { below originator prices to be } \\
\text { reimbursed, the second and the third generics at least } 15 \% \text { cheaper than the first } \\
\text { generic, with the price of the fourth generic } 10 \% \text { lower than the second (till January } \\
2015 \text { - } 30 \% \text { below originator prices to be reimbursed, the second at least } 15 \% \text { cheaper } \\
\text { than the first, with the price of third generic } 10 \% \text { lower than the second). Where more } \\
\text { than three products with the same INN are reimbursed, the originator must not be } \\
\text { priced higher than } 10 \% \text { (till July } 2017 \text { - } 40 \% \text { ) above the cheapest generic to continue } \\
\text { to be reimbursed. } \\
\text { There is an external reference pricing system in Lithuania based on } 8 \text { countries - } \\
\text { Latvia, Estonia, Bulgaria, Poland, Romania, Czech Republic, Slovakia and Hungary. } \\
\text { The declared manufacturer price must be within a } 95 \% \text { average price of the reference } \\
\text { countries to be reimbursed across indications. } \\
\text { There are no differences in the pricing regulations depending on the disease area, e.g. } \\
\text { cancer vs. non-cancer. } \\
\text { No changes are envisaged to the pricing of oral generic cancer medicines in the short } \\
\text { to medium term. There will be some changes for all reimbursed medicines from July } \\
2018: \text { co-payment for all reimbursed medicines can be higher than } 20 \% \text { of the } \\
\text { reimbursed price or } € 4 \text {. }\end{array}$ \\
\hline & $\begin{array}{l}\text { There is an external reference price system for medicines including generics in } \\
\text { Albania. The reference countries are Croatia, Italy, Macedonia, Serbia and Slovenia. } \\
\text { There are no differences in the pricing regulations for generics for cancer as opposed } \\
\text { to other disease areas. } \\
\text { Most of oral cancer medicines are reimbursed by the state, with the generic with the } \\
\text { lowest price is the first alternative for the patient with no differences by indication. } \\
\text { No changes are envisaged to the pricing of oral generic cancer medicines in the short } \\
\text { to medium term }\end{array}$ \\
\hline $\begin{array}{l}\text { Norway }(99,100) \\
\text { (prescriptive) }\end{array}$ & $\begin{array}{l}\text { Norway introduced the 'Stepped Price Model' for generics in } 2005 \text { alongside incentives } \\
\text { to pharmacies to enhance substitution. The 'Stepped Price' became the maximum } \\
\text { price paid by the Norwegian National Insurance System (NIS) for the molecule. The } \\
\text { first generic(s) are priced initially } 35 \% \text { below the maximum pre-patent loss prices up to } \\
12 \text { months before generic alternatives. Six months after the first generic is launched, } \\
\text { there is a } 59 \% \text { to } 81 \% \text { price reduction. The extent of the reduction depends on whether } \\
\text { current annual sales estimates are }<\text { or }>100 \text { mnNOK. } 12 \text { months or more after the } \\
\text { second step, the price decreases to } 69 \% \text { for annual sales between } 15 \mathrm{mn} \text { and } 30 \mathrm{mn} \\
\text { NOK, } 88 \% \text { for } 30-100 \mathrm{mn} \text { NOK and } 90 \% \text { reduction for annual reimbursed sales }> \\
100 \mathrm{mn} \text { NOK after the second cut. } \\
\text { These pricing regulatons apply to all generics whether for oncology or not. } \\
\text { Typically there is no difference in pricing approaches whether one indication is } \\
\text { patented or not especially with cancer medicines which are typically dispensed in } \\
\text { hospitals and subject to additional discounts and rebates with the manufacturers. } \\
\text { In May } 2017 \text {, all cancer drugs were transfered to the hospital budgets. As a result of } \\
\text { this, the pricing mechanism of stepped price was replaced by a tender system with } \\
\text { secret price discounts. }\end{array}$ \\
\hline $\begin{array}{l}\text { Slovakia (38) } \\
\text { (mixed) }\end{array}$ & $\begin{array}{l}\text { Medicines can only be included in the reimbursed list if their prices are lower than the } \\
\text { average of the three lowest prices in the EU. } \\
\text { With respect to generics, the price of the first generic seeking reimbursement must be } \\
\text { lower by a minimum of } 35 \% \text { compared with the originator in the same reference group } \\
\text { or cluster. } \\
\text { In addition, physicians are obliged to prescribe by INN name and pharmacists must } \\
\text { inform patients about cheaper alternatives when filling a prescription. Should the } \\
\text { physician not provide any reason why a generic cannot be used vs. the originator, the } \\
\text { patient may choose the less expensive option under the supervision and advice of a } \\
\text { pharmacist. }\end{array}$ \\
\hline
\end{tabular}




\begin{tabular}{|c|c|}
\hline & These pricing regulatons apply to all generics whether for oncology or not. \\
\hline $\begin{array}{l}\text { Serbia (101) } \\
\text { (mixed) }\end{array}$ & $\begin{array}{l}\text { Serbia has introduced an external reference pricing system for medicines including } \\
\text { generics. These are based on three reference countries: Croatia, Slovenia and Italy. } \\
\text { Once generics become available, the originator company must lower its price to the } \\
\text { same price as the generics to still be reimbursed, with subsequent generics priced } \\
\text { similar or } 10 \% \text { lower than the previous generic. The lowest priced product } \\
\text { subsequently establishes the reference price for the molecule. This applies to all } \\
\text { generics whether for cancer indication or not. } \\
\text { There should be no difference in pricing approaches whether one indication is patented } \\
\text { or not especially with cancer medicines typically dispensed in hospitals subject to } \\
\text { additional discounts and rebates from manufacturers. } \\
\text { These pricing regulatons apply to all generics whether for oncology or not. } \\
\text { The main envisaged difference in the medium term is the likely changes in the } \\
\text { reference countries. }\end{array}$ \\
\hline $\begin{array}{l}\text { Bulgaria }(96,98) \\
\text { (mixed) }\end{array}$ & $\begin{array}{l}\text { The price of the first and following generics should not exceed } 70 \% \text { of the price of the } \\
\text { originator. Subsequently to stimulate competition, as a result of internal reference } \\
\text { pricing, the lowest price per DDD is reimbursed for a particular INN. The ex-factory } \\
\text { price may not be higher than the BGN equivalent of the lowest ex-factory price for the } \\
\text { same medicinal product in the reference countries (total number is } 17 \text { - } 10 \text { principal } \\
\text { countries with } 7 \text { additional reference countries). The ceiling retail price is calculated as } \\
\text { a sum total of the manufacturer price, wholesaler price and retail price combined with } \\
\text { VAT of } 20 \% \text {. The prices are published on the web page of the National Council on } \\
\text { Prices and Reimbursement (www.ncpr.bg). Confidential discounts can subsequently be } \\
\text { negotiated with hospitals and National Health Insurance Fund. } \\
\text { There are no differences in the pricing rules between generics for oncology or other } \\
\text { medicinal products. } \\
\text { Reimbursed medicines can only be used according to the indications included in the } \\
\text { SPC. If there is exclusivity for some indications, this is respected in reimbursement and } \\
\text { prescribing deliberation. As a result, the originator might be more widely utilized for } \\
\text { more indications than generics. } \\
\text { No major differences are envisaged in the short to medium term }\end{array}$ \\
\hline $\begin{array}{l}\text { Austria }(61,85, \\
102,103) \text { (mixed) }\end{array}$ & $\begin{array}{l}\text { Prior to April } 2017 \text { the price reduction requirement for the first generic was } 48 \% \text { below } \\
\text { the price of the originators, } 15 \% \text { lower still for the second and } 10 \% \text { lower still for the } \\
\text { third. After April } 2017 \text {, the first generic 'follower' is priced at least } 50 \% \text { below the price } \\
\text { of the originator. The second and each subsequent 'follower' generic is required to } \\
\text { have a price difference related to the previous molecule including a generic, i.e. the } \\
\text { price of the second generic 'follower' has to be } 18 \% \text { lower than the first 'follower' and } \\
\text { the price of the third 'follower' has to be } 15 \% \text { lower than the price of the second } \\
\text { 'follower' to be reimbursed. The price of the originator has to be reduced by at least } \\
30 \% \text { within three months after the inclusion of the first generic follower into the } \\
\text { reimbursement list otherwise it will be delisted. If there is a 3rd follower, all marketing } \\
\text { authorisation holders of that product have to decrease the price to the price of the 3rd } \\
\text { follower for continued reimbursement. Further generics have to offer price deductions } \\
\text { of at least } € 0.10 / \text { pack to be included in the reimbursement code. } \\
\text { There are no differences in the pricing regulations between oncology and other } \\
\text { medicinal products regarding the pricing of generics. } \\
\text { In Austria, physicians are obliged to prescribe the most economical alternative if they } \\
\text { are both therapeutically suitable for treatment so this will typically be the generic } \\
\text { whatever the indication. } \\
\text { The current higher discount rates for generics are valid until the } 31 \text { st of December } \\
2021 . \text { If there is no legal amendments, the rates will be reduced to those prior April } \\
2017 \text { levels at } 1 \text { st of January } 2022 \text {. }\end{array}$ \\
\hline $\begin{array}{l}\text { Sweden (104- } \\
\text { 106) (market } \\
\text { forces) }\end{array}$ & $\begin{array}{l}\text { Generic substitution is mandatory in Sweden unless concerns, with the pharmacy } \\
\text { obligated to dispense the least expensive pharmaceutical product regardless of what } \\
\text { product is prescribed. The preferred product (typically one of the branded generics) is } \\
\text { appointed through a monthly auction guaranteeing a high level of sales the following } \\
\text { month. The pharmaceutical company must ensure availability of the pharmaceutical }\end{array}$ \\
\hline
\end{tabular}




\begin{tabular}{|c|c|}
\hline & $\begin{array}{l}\text { during the entire price period and that the expiring date of the product meets the } \\
\text { minimum requirements. There are also two back-up products that pharmacies can } \\
\text { switch to if it is not possible to obtain the cheapest alternative. } \\
\text { There are no differences in the regulations between oncology and other medicinal } \\
\text { products, and there is currently no indication monitoring. Consequently, no possibility to } \\
\text { differentiate between indications if one is patent protected but not the other. } \\
\text { No major changes are envisaged in the short to medium term }\end{array}$ \\
\hline $\begin{array}{l}\text { Greece (107) } \\
\text { (mixed) }\end{array}$ & $\begin{array}{l}\text { According to Law } 4337 / 2016 \text {, the price of the originator medicine is predicted to be } \\
50 \% \text { of its price pre-patent loss (off-patent medicine), while a generic should be } 65 \% \text { of } \\
\text { the price of an off-patent medicine. However, Ministerial Decision } 28408 / 19.4 .2016 \\
\text { states that generics may not be more expensive than off-patent medicines. Even after } \\
\text { the implementation of the ministerial decision, it has been observed that some generics } \\
\text { are more expensive than off-patent medicines by up to } 30 \% \text {. } \\
\text { This is being addressed with price reductions; however, there are still concerns with the } \\
\text { pricing of generics in Greece. } \\
\text { Typically, there are no differences in the regulations between oncology and other } \\
\text { medicinal products, with similar prices across indications. }\end{array}$ \\
\hline Belgium (mixed) & $\begin{array}{l}\text { Under the internal reference price system from } 1^{\text {st }} \text { March } 2016 \text { (the so-called "patent } \\
\text { cliff"), the reference price is set by reducing the price of the originator by } 43.64 \% \text { (or by } \\
51.52 \% \text { for fully reimbursed drugs). } \\
\text { The price of any medicine in the reference cluster must be lower than the reference } \\
\text { price plus a safety margin (this safety margin consists of } 25 \% \text { of the reference price, } \\
\text { with a maximum of } € 5 \text { ). Patients have to pay an additional co-payment to cover any } \\
\text { additional cost for their preferred product over and above the reference price for the } \\
\text { molecule if this occurs, which is not indication specific. } \\
\text { Originator and generic drugs in the reference cluster are also subjected to a price } \\
\text { reduction imposed on "old" drugs, which consists of an additional reduction of } 19 \% \\
\text { after } 12 \text { years of reimbursement and } 2.41 \% \text { after } 15 \text { years, unless these reductions } \\
\text { have previously been applied. } \\
\text { There are no differences between generics for oncology and other disease areas, and } \\
\text { no changes are envisaged in the short term. }\end{array}$ \\
\hline $\begin{array}{l}\text { Netherlands (49) } \\
\text { (market forces) }\end{array}$ & $\begin{array}{l}\text { Introduction of the preference pricing policy in } 2008 \text { whereby only the cheapest } \\
\text { generics would be reimbursed, with patients having to cover the costs themselves for a } \\
\text { non-preferred drug. Tenders are conducted every three months. } \\
\text { In the case of cancer medicines, typically these are dispensed in hospitals with the } \\
\text { hospitals generally achieving additional discounts. This will apply whatever the } \\
\text { indication. } \\
\text { No changes are envisaged in the short to medium term }\end{array}$ \\
\hline $\begin{array}{l}\text { Romania (96) } \\
\text { (mixed) }\end{array}$ & $\begin{array}{l}\text { The maximum medicine price (CANAMED), approved by MoH, is the lowest price from } \\
12 \text { reference EU countries: Austria, Belgium, Bulgaria Czech, Republic, Germany, } \\
\text { Greece, Hungary, Italy, Lithuania, Poland, Slovenia, Spain. The maximum price for } \\
\text { generics } \leq 65 \% \text { of the originator. There are no differences regarding CANAMED price } \\
\text { approval between generics for oncology and other disease areas. MoH Ord. nr. } \\
75 / 2009, \text { modified and updated, replaced by MoH Ord. } 368 / 2017 \text {, modified and } \\
\text { updated [http://legislatie.just.ro/Public/DetaliiDocumentAfis/195939]. } \\
\text { The settlement price (reimbursed by the National Health Insurance House - NHIH) for } \\
\text { oncology drugs is } 100 \% \text { of the originator price if no generics, } 120 \% \text { of the cheapest } \\
\text { generic if one exists, or the actual price for the generics if lower than the settlement } \\
\text { price - Ord. } 1605 / 875 / 2014, \text { updated. } \\
\text { [http://legislatie.just.ro/Public/DetaliiDocumentAfis/164191]. This applies whatever the } \\
\text { indication. The exception is imatinib in some indications where NHIH is reimbursing the } \\
\text { full price. } \\
\text { There are no differences in the regulations between oncology and those for other } \\
\text { medicinal products. }\end{array}$ \\
\hline
\end{tabular}




\begin{tabular}{|c|c|}
\hline & $\begin{array}{l}\text { Future initiatives include greater encouragement of generic medicines through } \\
\text { decreasing originator prices by } 35 \% \text { when the patent expires (short term). Eventually, a } \\
\text { differentiated clawback tax for originators and generics (medium term). }\end{array}$ \\
\hline Poland (mixed) & $\begin{array}{l}\text { The official selling price for the unit dose of the first generic equivalent cannot be higher } \\
\text { than } 75 \% \text { of the official selling price for the unit dose of the originator reimbursed in a } \\
\text { given indication. When the first generic enters the reimbursement list, the } \\
\text { reimbursement limit is set to the generic price which leads to a reduction of the refund } \\
\text { for all preparations in a given limit group. Moreover, after the market exclusiveness of } \\
\text { an originator expires, its price is reduced by at least } 25 \% \text { (even if no generic is } \\
\text { available). } \\
\text { There are no differences between generics for oncology versus other disease areas. } \\
\text { In case of imatinib two different reimbursement paths exist: one for GIST (Glivec }{ }^{\circledR} \\
\text { patent protection) and one for other indications. In the patented indication, only the } \\
\text { originator is reimbursed and its price is stable and not influenced by generic availability. } \\
\text { In indications that are not patent protected, the reimbursement limit is set to the generic } \\
\text { prices. } \\
\text { It is difficult to say if there will be any changes in the pricing of generics in the short to } \\
\text { medium term }\end{array}$ \\
\hline $\begin{array}{l}\text { Spain }(61,82, \\
\text { 108) (market } \\
\text { forces) }\end{array}$ & $\begin{array}{l}\text { Market forces help drive down generic prices, enhanced by pharmacists mandated to } \\
\text { dispense the cheapest molecule once multiple sources are available coupled with INN } \\
\text { prescribing with no opportunity for additional co-payments by patients for a more } \\
\text { expensive drug. The follower generic typically has to be cheaper to be reimbursed and } \\
\text { used. The reference price (which is paid by the state) is the price of the cheapest } \\
\text { product. Consequently to be reimbursed, the originator must reduce its price to the } \\
\text { generic price. } \\
\text { There are no differences between generics for oncology versus other disease areas. } \\
\text { Typically originators will reduce their prices to be reimbursed; consequently, the issue } \\
\text { of differential pricing per indication does not typically arise. } \\
\text { No changes are envisaged at least in the short term. }\end{array}$ \\
\hline Italy (109) (mixed) & $\begin{array}{l}\text { Since } 1 \text { July } 2013 \text {, a new, voluntary system for pricing and reimbursement of generic } \\
\text { medicines has been introduced. The price of the first generic will be automatically } \\
\text { determined based on (i) the price of the originator medicine at the time of application } \\
\text { and (ii) the level of pharmaceutical expenditure of the medicine in the } 3 \text { years prior to } \\
\text { patent expiry. This has resulted in } 8 \text { discount tiers for fully reimbursed medicines } \\
\text { (Category A) between } 45 \% \text { to } 75 \% \text {. A generic medicine will be granted automatic } \\
\text { pricing and reimbursement approval if the requested price is below this discounted } \\
\text { maximum price. There have also been additional price cuts to help the authorities stay } \\
\text { with agreed pharmaceutical expenditure limits. } \\
\text { There are no differences in pricing arrangements between generics for oncology } \\
\text { versus other disease areas. } \\
\text { Internal reference pricing system is not dependent on indications although the } \\
\text { reimbursed indications have to be respected; with patients required to pay the } \\
\text { difference for a more expensive originator if wished } \\
\text { No major changes are envisaged in the short to medium term }\end{array}$ \\
\hline $\begin{array}{l}\text { France (104) } \\
\text { (prescriptive) }\end{array}$ & $\begin{array}{l}\text { The price of the first generic must be } 60 \% \% \text { below the originator (55\% before } 2015 \text {, } \\
60 \% \text { from } 2015) \text {, with prices falling by an additional } 7 \% \text { after } 18 \text { months, with } \\
\text { pharmacists incentivised to substitute generics when an originator is prescribed. In } \\
\text { addition, there is a } 20 \% \text { decrease in the price of the originator when generics are first } \\
\text { introduced and an additional decrease of } 12.5 \% \text { after } 18 \text { months. } \\
\text { These regulations apply to all generics whether for cancer indications or not. } \\
\text { No major changes are envisaged in the short to medium term. }\end{array}$ \\
\hline $\begin{array}{l}\text { UK }(110-113) \\
\text { (market forces) }\end{array}$ & $\begin{array}{l}\text { There is free pricing for generics in the UK. Ambulatory care reimbursed prices are } \\
\text { based on the tariff price coupled with free market competition, which leads to further } \\
\text { price reductions over time. }\end{array}$ \\
\hline
\end{tabular}




\begin{tabular}{|l|l|}
\hline $\begin{array}{l}\text { In England, the 'M' (Manufacturer) and 'W' (Wholesaler) scheme was introduced in } \\
\text { April } 2005 \text { to increase transparency in the manufacture and pricing of generics, as well } \\
\text { as discounts and other incentives offered by the manufacturers of generics to } \\
\text { wholesalers and pharmacists to enhance the stocking and dispensing of particular } \\
\text { generics. As a result, prices of high volume generics can be as low as 3\% of pre-patent } \\
\text { loss originator prices }\end{array}$ \\
$\begin{array}{l}\text { There are no differences in pricing arrangements between generics for oncology } \\
\text { versus other disease areas. In addition, high INN prescribing across indications. } \\
\text { There is high INN prescribing in the UK (98-99\% where no controversies) and there } \\
\text { have been concerns with the prescribing of generics and originators when some } \\
\text { indications are patent protected, e.g. pregabalin. However, this is not universal and no } \\
\text { concerns yet for oral cancer medicines. } \\
\text { The major change in the future in the UK is there will be greater scrutiny over generic } \\
\text { prices where there is limited or no competition and where there are perceived high } \\
\text { unjustified prices. This will result in negotiated price reductions for usage and funding in } \\
\text { the UK. }\end{array}$ \\
\hline
\end{tabular}

\subsubsection{Pricing of oral cancer medicines if one indication has lost its patent}

There were generally no issues with the pricing and usage of oral generic cancer medicines once one indication had lost its patent but not the other indication(s) (Table 1); however, this was not universal. There is similar to the situation in Germany once the first indication for a multiple sourced product has lost its patent (61), i.e. the generic medicine can be prescribed across all indications at the discounted price versus the originator. However, this is different to the situation that existed with pregabalin among a number of European countries where the generic could only be prescribed for epilepsy and the originator must be prescribed and reimbursed accordingly for neuropathic pain (61).

This situation is encouraging for maximising savings following generic availability given the considerable savings that can be achieved with the introduction of generics (Table 3), and will be closely monitored in the future. This includes procured medicines for distribution in hospitals.

\subsubsection{Substitution of oral cancer medicines and initiatives to encourage their prescribing}

It was also encouraging to see that once generics became available, there were no concerns with substitution with the selected oral generic cancer medicines (Table 1). This is similar to the general situation for cancer medicines (28). Consequently, originators can be substituted with generics without compromising care. This is again important for maximising savings once generics become available.

Initiatives to encourage the prescribing of generics in preference to originator cancer medicines among the various European countries (Box 2) were similar to those for generic medicines in generally.

\section{Box 2 - Initiatives across Europe to enhance the prescribing of generics versus originators}

- The cheapest priced medicine is the first alternative for patients (Albania)

- Additional patient co-payments to cover any price difference if the patient prefers an originator versus a generic, e.g. Bulgaria, Latvia, Serbia, and Slovenia

- Incentives for physicians to prescribe generics rather than originators, e.g. Austria

- Incentives for pharmacists to substitute with a generic if an originator is prescribed, e.g. France

- Encouraging INN prescribing, e.g. Estonia, Lithuania, Romania and the UK.

NB: INN = International non-proprietary prescribing

\subsection{Price reductions with generics over time and with originators, as well as the influence of population size and market forces}

Prices for originator 400mg imatinib were similar in Western European countries in 2015 before generic availability (Figure 1). Generic imatinib was already available in CEE countries before this 
date, e.g. in Albania, Estonia, Latvia, Lithuania, Romania, Serbia and Slovakia generic imatinib was available in 2013 or before and in Poland and Slovenia in 2014. Generic capecitabine and flutamide were already available in a number of Western European countries in 2013. The other three oral anticancer medicines were already available as generics among Western European countries before 2013.

Figure 1 - Price per tablet (Euros) for imatinib $400 \mathrm{mg}$ (originator) among Western European countries in 2015 (countries in order of their population size)

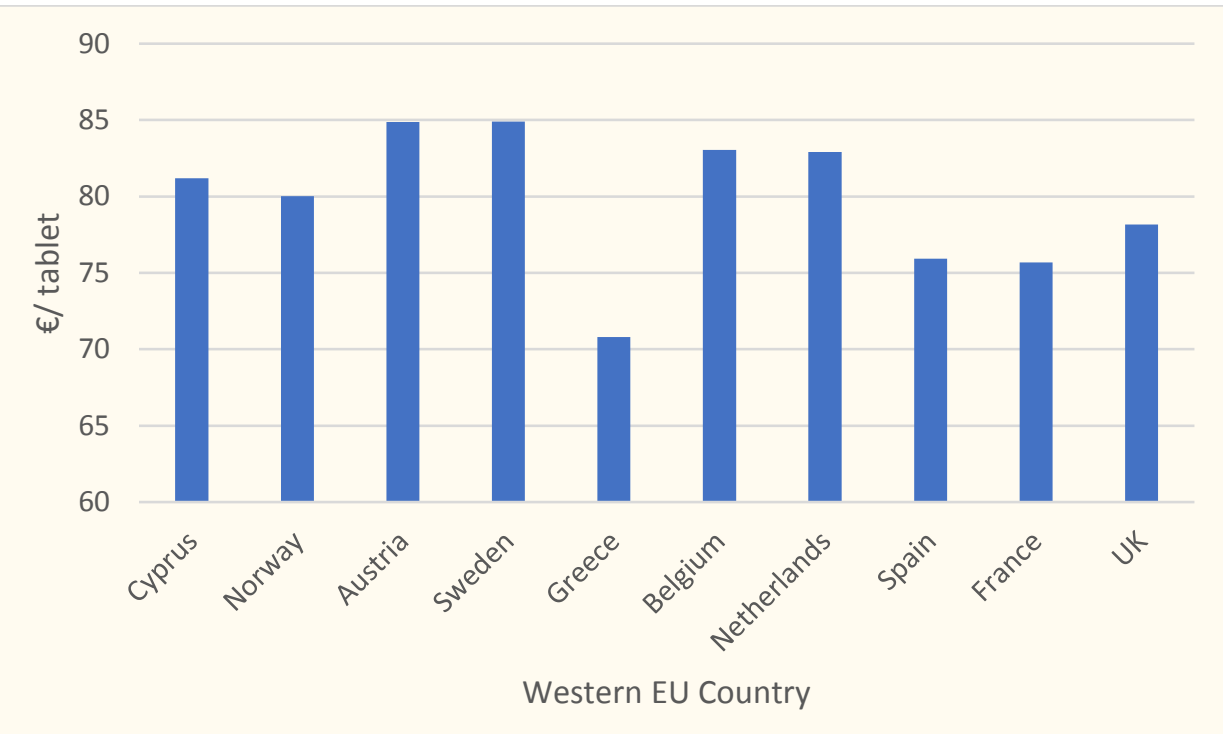

NB: Cyprus 2012

As expected, there were differences in the prices of the generics for capecitabine $(500 \mathrm{mg})$, flutamide (250mg), imatinib (400mg) and temozolomide (20mg and 250mg) in 2017 among the European countries where these generics were available (Table 2), reflecting differences in the approaches to the pricing of oral generics among the various European countries (Table 1).

Table 2 - Price per tablet (Euros) for four generic oral anti-cancer medicines in 2017 amongst the European countries where data was available (countries in order of their population size)

\begin{tabular}{|l|c|c|c|c|c|}
\hline & Capecitabine 500 & Flutamide 250 $\mathbf{~ m g}$ & $\begin{array}{c}\text { Imatinib } \\
\mathbf{4 0 0 \mathbf { m g }}\end{array}$ & $\begin{array}{c}\text { Temozolomide } \\
\mathbf{2 0} \mathbf{m g}\end{array}$ & Temozolomide 250mg \\
\hline Malta & 0.31 & 0.38 & & 4.50 & \\
\hline Republic Srpska & & & & 4.73 & \\
\hline Cyprus & & & 1.82 & & \\
\hline Estonia & 0.52 & & 27.72 & 3.86 & 48.19 \\
\hline Kosovo & 0.83 & & 2.42 & & 50.00 \\
\hline Latvia & 0.61 & 0.53 & 3.44 & 3.38 & \\
\hline Slovenia & 0.87 & & 24.28 & 4.71 & 59.98 \\
\hline Lithuania & 0.66 & & 6.62 & 3.46 & 41.42 \\
\hline Albania & 0.74 & 0.39 & 8.00 & & 40.93 \\
\hline Norway & 1.87 & & 53.00 & 10.00 & 85.13 \\
\hline Slovakia & 0.55 & 0.33 & 31.99 & 3.28 & 71.13 \\
\hline Serbia & & & 6.89 & & \\
\hline Bulgaria & 0.45 & 0.28 & & 3.61 & \\
\hline Austria & 0.59 & 0.38 & 9.50 & 3.67 & 35.66 \\
\hline Sweden & 0.66 & 0.39 & 3.28 & 4.22 & 25.87 \\
\hline
\end{tabular}




\begin{tabular}{|l|c|c|c|c|c|} 
Greece & 0.90 & 0.23 & 21.13 & 4.19 & 33.59 \\
\hline Belgium & 1.41 & 0.49 & 32.80 & & \\
\hline Netherlands & 1.03 & 0.34 & 45.84 & 4.80 & 40.20 \\
\hline Romania & 0.41 & 0.27 & 7.20 & 2.28 & 41.15 \\
\hline Poland & 0.21 & 0.16 & 0.92 & 0.86 & 9.47 \\
\hline Spain & 0.96 & 0.60 & 49.25 & 7.46 & 93.18 \\
\hline Italy & 1.78 & 0.63 & & 11.86 & 148.21 \\
\hline France & 1.27 & 0.91 & 32.87 & 17.64 & 220.52 \\
\hline UK & 2.46 & 1.43 & 71.30 & 12.42 & 155.29 \\
\hline
\end{tabular}

NB. In some countries only imatinib $100 \mathrm{mg}$ was available, e.g. Republic of Srpska at $€ 0.645 /$ tablet. In addition, price for capecitabine $500 \mathrm{mg}$ was $€ 0.297$ in 2016

There were no differences in the prices of capecitabine $(500 \mathrm{mg})$, flutamide $(250 \mathrm{mg})$, imatinib $(400 \mathrm{mg})$ and temozolomide $(20 \mathrm{mg}$ and $250 \mathrm{mg}$ ) when the countries were broken down into small, medium or large populations (Table 2A) apart from generic imatinib for European countries with large populations, i.e. capecitabine ( $p=0.372$ for medium and 0.100 for large), flutamide $(p=0.70$ for medium and 0.385 for large), imatinib ( $p=0.249$ for medium and 0.037 for large), temozolomide $20 \mathrm{mg}(p=$ 0.764 for medium and 0.085 for large) and temozolomide $250 \mathrm{mg}(p=0.951$ for medium and 0.105 for large). Prices for generic capecitabine $(p=0.007)$, generic imatinib $(p=0.015)$ and temozolomide $20 \mathrm{mg}$ $(p=0.015)$ were though typically appreciably higher when combined among Western European countries compared with CEE countries. However, this was not the case for flutamide or temozolomide $250 \mathrm{mg}$. This will change for generic imatinib as prices fall among the large Western European countries over time, e.g. generic imatinib in Scotland by March 2018 was already $89.1 \%$ below pre-patent loss prices having only been made available in 2016.

Overall in 2017, the differences in the prices of generics of capecitabine $(500 \mathrm{mg})$, flutamide $(250 \mathrm{mg})$, imatinib $(400 \mathrm{mg})$ and temozolomide $(20 \mathrm{mg}$ and $250 \mathrm{mg}$ ) among the different European countries (Table 2) appear to be a reflection of the differences in the country's pricing approaches towards generics (Table 1) rather than population size when broken down into small, medium or large, as well as the timing of generic availability. These findings are similar to those with generic busulfan, chlorambucil, cyclophosphamide and melphalan (Table 4), and confirm this trend certainly for oral generic cancer medicines.

There also appears to be no correlation in terms of the price reductions seen for generic capecitabine, flutamide, imatinib or temozolomide in 2017 versus 2013 originator prices with population sizes, i.e. appreciable price reductions over time were not confined to European countries with higher populations (Table 3). There was also no significant difference in the percentage reduction between Western and CEE countries for capecitabine, flutamide, imatinib or temozolomide. 
Table 3 - \% change in prices of generic capecitabine, flutamide, imatinib and temozolomide in 2017 vs originator prices in 2013 among the European countries where this data is available (countries in order of their population size)

\begin{tabular}{|c|c|c|c|c|c|}
\hline & $\begin{array}{l}\text { Capecitabine } \\
500 \mathrm{mg}\end{array}$ & Flutamide $250 \mathrm{mg}$ & Imatinib $400 \mathrm{mg}^{*}$ & Temozolomide $20 \mathrm{mg}$ & Temozolomide $250 \mathrm{mg}$ \\
\hline Malta* & & & -95.6 & & \\
\hline Cyprus** & & & -97.8 & & \\
\hline Estonia & -85.1 & & -67.4 & -59.4 & -59.9 \\
\hline Latvia & -80.3 & & -68.9 & & \\
\hline Slovenia & -69.6 & & -65.6 & -23.5 & 0.0 \\
\hline Lithuania* & -77.2 & & -84.8 & & \\
\hline Albania & -67.1 & & -89.9 & & -77.1 \\
\hline Norway & -45.0 & & -40.2 & -14.7 & -16.1 \\
\hline Slovakia** & -81.2 & -26.2 & $-59.2 \%$ & $-52.3 \%$ & $-30.5 \%$ \\
\hline Serbia & & & -63.7 & & \\
\hline Bulgaria & -85.3 & & & -65.0 & \\
\hline Austria & -81.3 & & -88.8 & -38.7 & -39.8 \\
\hline Sweden & -80.3 & -12.4 & -96.4 & -73.6 & -69.5 \\
\hline Greece & -66.7 & -4.2 & -69.6 & -37.5 & -62.1 \\
\hline Belgium & -59.4 & -23.7 & -62.8 & & \\
\hline Netherlands & -66.0 & 0.0 & -41.7 & -70.5 & -79.6 \\
\hline Romania* & -86.8 & & -92.4 & -64.2 & \\
\hline Poland & -93.1 & & -98.8 & -80.7 & -78.7 \\
\hline Spain & -67.0 & & -35.1 & -15.3 & \\
\hline Italy* & -60.0 & -19.6 & -71.5 & -53.0 & -53.0 \\
\hline France & -52.8 & -3.2 & -57.3 & 0.0 & 0.0 \\
\hline UK & -7.3 & & 3.4 & -25.2 & 22.2 \\
\hline
\end{tabular}

NB: ${ }^{*}$ In a small number of countries only $100 \mathrm{mg}$ imatinib was available - so their $\%$ reduction is recorded; ${ }^{* *} 2012$ originator prices

If anything, there was a greater reduction in the prices of generic capecitabine (Figure 2 ) in countries with a mixed approach to the pricing of generics versus those with market forces $(p=0.035)$ and prescriptive $(p=0.041)$ approaches. 
Figure 2 - \% reduction in capecitabine prices (generic prices in 2017 vs. originator prices in 2013) among European countries where this data was available

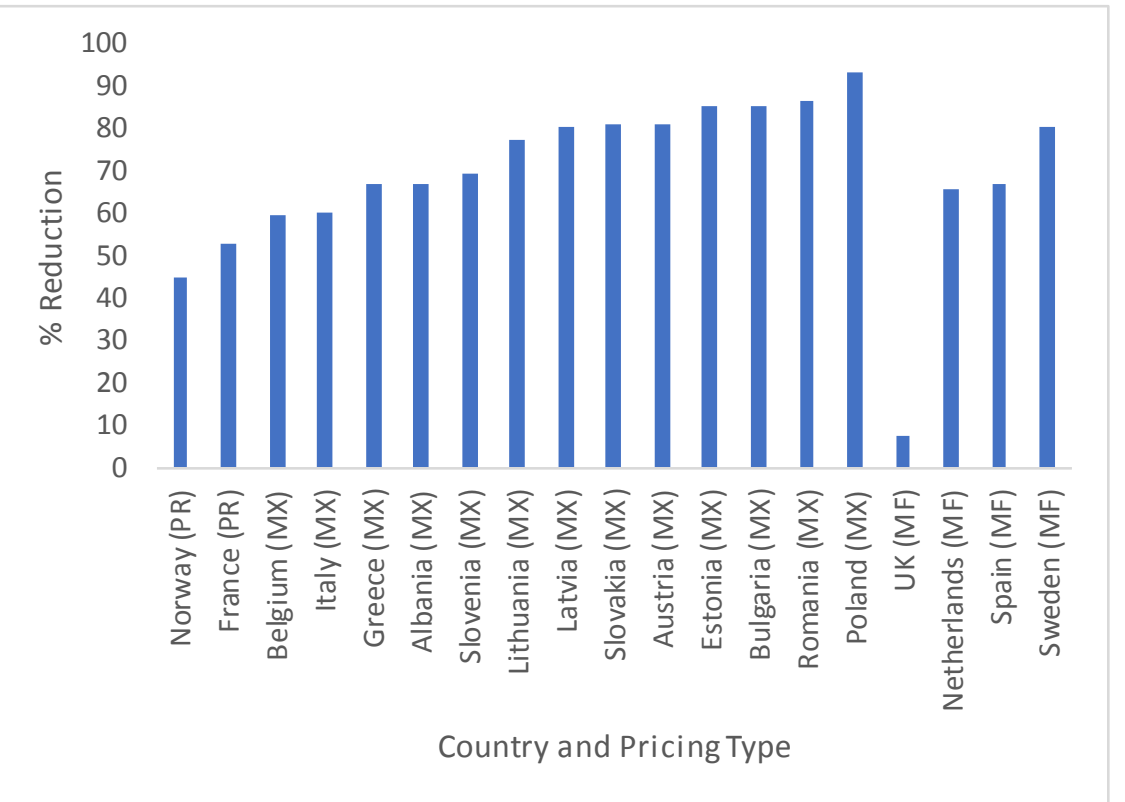

NB: $P R=$ prescriptive pricing, $M F=$ market forces,$M X=$ mixed approach

This was not the case for generic imatinib (Figure 3 ) although there was a trend $(p=0.079$ for market forces and 0.119 for prescriptive pricing approaches). However, this may change as prices of generic imatinib fall in the Netherlands, Spain, Sweden and the UK, e.g. as mentioned generic imatinib in Scotland was already $89.1 \%$ below pre-patent loss prices by March 2018 having only been made available in 2016.

Figure 3 - \% reduction in imatinib prices (generic prices in 2017 vs. originator prices in 2013) among European countries where this data was available

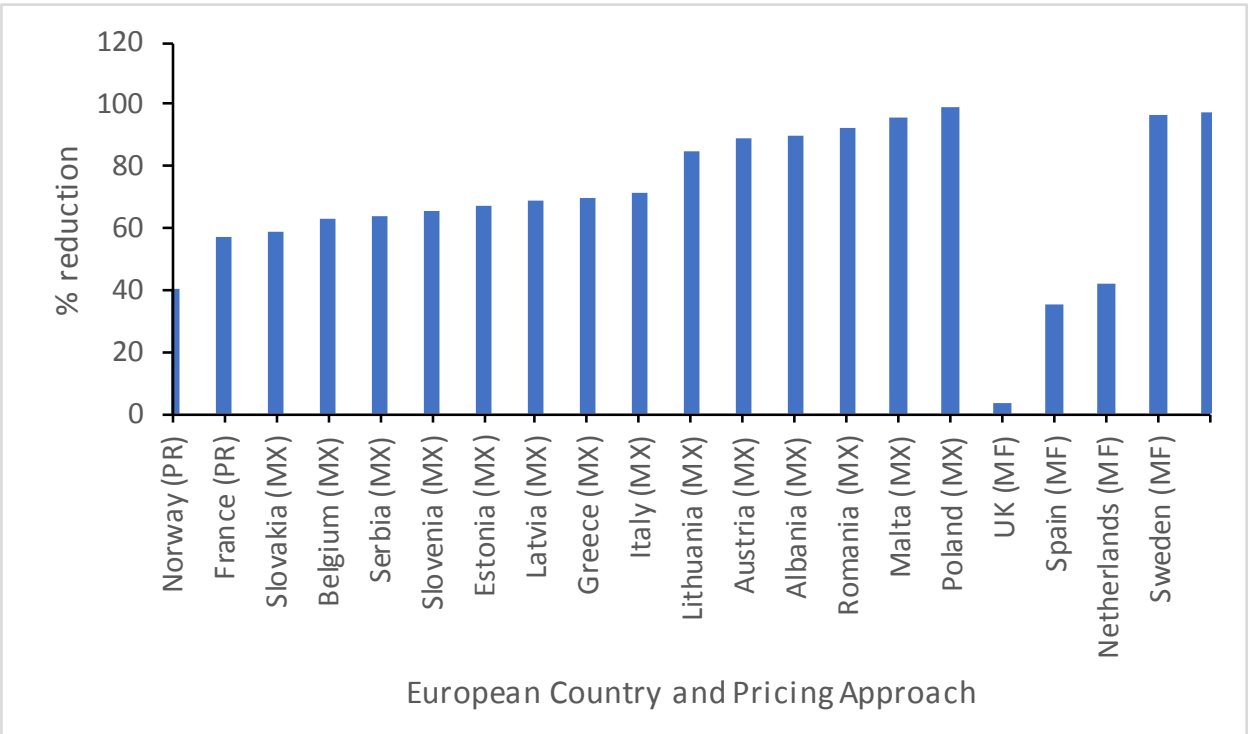

NB: $\mathrm{PR}=$ prescriptive pricing, $\mathrm{MF}=$ market forces, $\mathrm{MX}=$ mixed approach. In addition, UK prices $89.1 \%$ reduction in March 2018 following greater competition 


\subsection{Price changes for generics with changes in the licence holder}

In recent years, the generic manufacturer Aspen has taken over the licence of busulfan, chlorambucil, and melphalan, and enjoyed market monopoly, with typically no generic competition, despite the loss of patent protection. Another pharmaceutical company, Baxter, has used a similar strategy with cyclophosphamide. Countries have typically been faced with having to either accept these higher prices or no longer procuring and/or reimbursing these medicines.

Figure 4 depicts current prices per tablet for these four oral generic anti-cancer medicines (2017) where these are currently listed and reimbursed since not all European countries currently reimburse these four medicines. There were no significant differences in the mean prices for these four anticancer medicines between Western and CEE countries. In the case of busulfan, there was a difference in current prices among European countries, with Western European countries typically having higher prices but this did not reach significance $(p=0.08)$. Population size again did not appear to influence subsequent prices.

Figure 4 - Price per tablet (Euros) for generic four oral anti-cancer medicines in 2017 where there have been manufacturer changes amongst 22 European countries (countries in order of their population size) where available

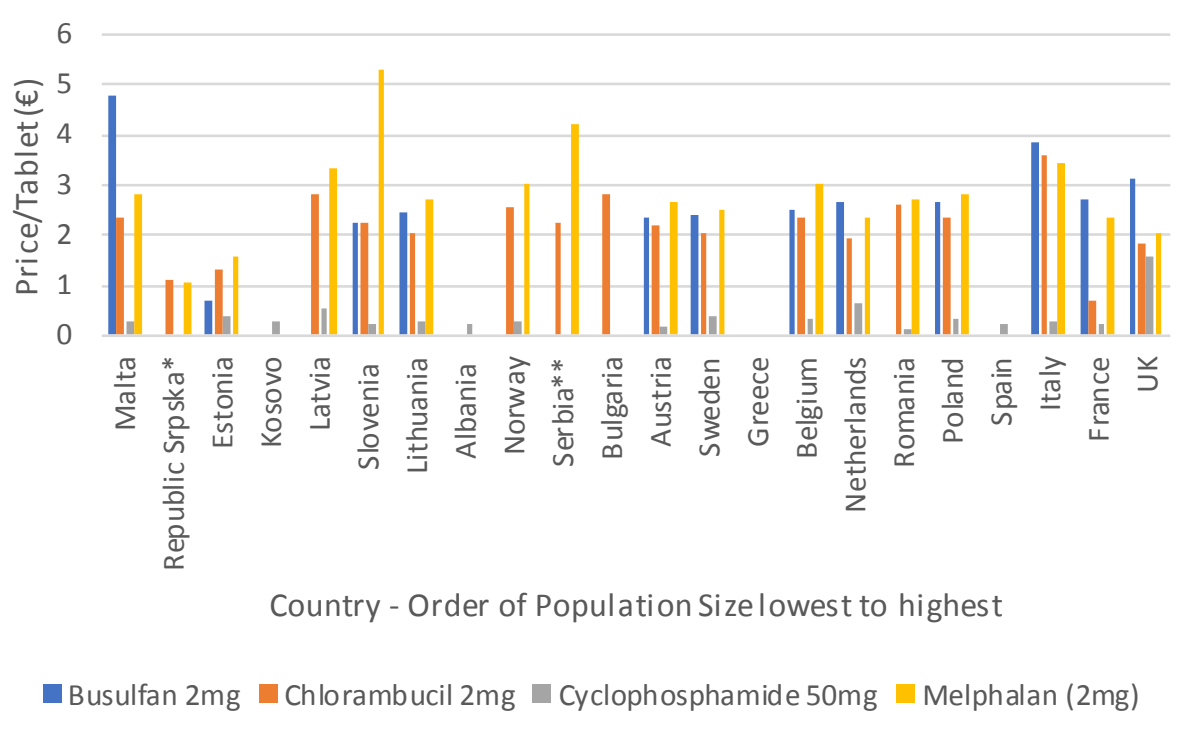

NB: No price means the anti-cancer medicine was not reimbursed in that country in 2017. *2016 price for melphalan; ${ }^{* *} 2015$ price In addition in Spain, there is no official reimbursed price for busulfan or chlorambucil as both products are imported and the price would depend on the country of export.

There were appreciable price rises in a number of other European countries following Aspen's purchase of busulfan, chlorambucil and melphalan from GlaxoSmithKline (Table 4). 
Table 4 - \% change in prices of busulfan, chlorambucil and melphalan in 2017 vs 2013 among the European Union countries where this data is available

\begin{tabular}{|c|c|c|c|c|c|c|}
\hline \multirow[t]{2}{*}{ Country } & \multicolumn{2}{|r|}{ Busulfan $2 \mathrm{mg}$} & \multicolumn{2}{|c|}{ Chlorambucil $2 \mathrm{mg}$} & \multicolumn{2}{|c|}{ Melphalan $2 \mathrm{mg}$} \\
\hline & \begin{tabular}{|c|}
$\%$ change \\
2017 vs 2013 \\
\end{tabular} & $\begin{array}{c}\text { Pre-2013 prices if } \\
\text { pertinent and known }\end{array}$ & $\begin{array}{c}\% \text { change } \\
2017 \text { vs. } 2013\end{array}$ & $\begin{array}{c}\text { Pre-2013 prices if } \\
\text { pertinent and known }\end{array}$ & \begin{tabular}{|c|}
$\%$ change \\
2017 vs. 2013
\end{tabular} & $\begin{array}{c}\text { Pre-2013 prices if } \\
\text { pertinent and known }\end{array}$ \\
\hline Malta & 28.4 & & 237.68 & & & \\
\hline Estonia & 187.5 & & 364.3 & & 226.5 & \\
\hline Latvia & & & 152.7 & & 201.2 & \\
\hline Slovenia & 427.4 & $\begin{array}{c}€ 0.23 \text { in } 2012 \text { before rising } \\
\text { to } € 0.423 \text { in } 2013 \text { and } € 2.23 \\
\text { in } 2014\end{array}$ & 0 & $\begin{array}{l}€ 0.368 \text { in } 2012 \text { before } \\
\text { rising to } € 2.24 \text { in } 2013\end{array}$ & 2619.39 & $\begin{array}{c}€ 0.16 \text { in } 2012 \text { before } \\
\text { rising to } € 1.96 \text { in } 2013 \\
\text { and } € 5.3 \text { in } 2014\end{array}$ \\
\hline Lithuania & 78.3 & & 42.4 & & 63.9 & \\
\hline Norway & & & -15.1 & & -15.2 & \\
\hline Austria & 0 & $\begin{array}{c}€ 0.22 \text { in } 212 \text { before } \\
\text { increasing to } € 2.35 \text { in } 2013\end{array}$ & 0 & $\begin{array}{c}€ 0.344 \text { before } \\
\text { increasing to } € 2.20 \text { in } \\
2012\end{array}$ & 0 & $\begin{array}{c}€ 0.509 \text { in } 2012 \text { before } \\
\text { increasing to } € 2.64 \text { in } \\
2013\end{array}$ \\
\hline Sweden & -9.6 & $\begin{array}{l}€ 0.08 \text { in } 2011 \text { before rising } \\
\text { to } € 0.44 \text { in } 2012 \text { and } € 2.70 \\
\text { in } 2013\end{array}$ & -15.70 & $\begin{array}{c}€ 0.24 \text { in } 2011 \text { before } \\
\text { increasing to €0.64 in } \\
2012 \text { and } € 2.45 \text { in } 2013\end{array}$ & -6.6 & $\begin{array}{c}€ 0.34 \text { in } 2011 \text { before } \\
\text { increasing to } € 0.68 \text { in } \\
2012 \text { and } € 2.83 \text { in } 2013\end{array}$ \\
\hline Belgium & 1591.4 & & 1122.4 & & 643.8 & \\
\hline Netherlands & 65.6 & & 90.7 & & 85.05 & \\
\hline Poland & -1.1 & & -3.3 & & -3.6 & \\
\hline Italy & 0 & & 1166.0 & & 1542.6 & \\
\hline France & -2.2 & $\begin{array}{c}€ 0.582 \text { in } 212 \text { before } \\
\text { increasing to } € 2.73 \text { in } 2013\end{array}$ & -5.4 & $\begin{array}{c}0.412 \text { in } 2010 \text { before } \\
\text { rising to } € 0.754 \text { in } 2011 \\
\text { and } € 0.74 \text { in } 2013 \\
\end{array}$ & -1.7 & $\begin{array}{c}€ 0.193 \text { in } 2012 \text { before } \\
\text { increasing to } € 2.37 \text { in } \\
2013 \\
\end{array}$ \\
\hline UK & -2.9 & $\begin{array}{c}\text { GBf0.21 in } 2011 \text { rising to } \\
\text { GBf2.61 }\end{array}$ & & 412.8 & Taken off th & e market as low sales \\
\hline
\end{tabular}

NB: No country listed means the anti-cancer medicine was not reimbursed in the country in 2017 or this data is not available, e.g. in Serbia no melphalan after 2015 with just 11 boxes of generic melphalan dispensed in 2015. In Slovakia, the prices of busulfan, chlorambucil, and melphalan, and busulfan appreciably increased in 2013. However, as the legislation does not permit significant increases, these dropped out of the reimbursement list. However, still available on special request. Generic chlorambucil was available in the Republic of Srpska from 2015 onwards (Celkeran and TherDose)

Similar price rises were seen in Germany during this period, e.g.:

- Busulfan (Myleran L01AB01): price until 30th April 2012: $€ 29.90$ for 25 x $2 \mathrm{mg}$ tablets $(€ 1.196 /$ tablet); thereafter $€ 109.11$ for 25 tablets ( $€ 4.364 /$ tablet), i.e. a $264.9 \%$ increase

- Melphalan (Alkeran - L01AA03): price until 30th April 2012: $€ 42.30$ for $25 \times 2$ mg tablets (€1.692/ tablet); thereafter €93.94 (€3.758), i.e.a $122.1 \%$ increase

- Chlorambucil (Leukeran - L01AA02): price until 30th April 2012: $€ 32.74$ for $25 \times 2$ mg tablets (€1.31/ tablet; thereafter $€ 80.03$ (€3.201), i.e. a $144.4 \%$ increase

With respect to cyclophosphamide, price rises have also been seen among some European countries between 2013 and 2017 following Baxter's involvement. These include Latvia (34.1\%), Austria $(38.2 \%)$, Norway $(44.8 \%)$, Austria $(50 \%)$, Slovenia $(56.3 \%)$, Slovakia $(57 \%)$, the Netherlands $(120.5 \%)$ and Sweden (132.0\%).

Overall there again appears to be no link between prices, geography and population size for these four medicines despite previous concerns. If anything, countries with smaller populations such as Estonia had lower prices than Belgium, Italy and the UK. This appears to be in contrast with previous publications (71), although this is in accordance with previous findings in Lithuania and the Republic of Srpska $(31,72)$.

The difference in prices of these four molecules between the countries in 2017 may well reflect differences in negotiations when the new company took over the molecules and re-launched them as a new originator at a higher price. Countries such as Estonia appeared successful in negotiating lower price increases for the re-launched medicines versus for instance Belgium, Italy and the UK.

However, as mentioned, the company was subsequently fined $€ 5.2 \mathrm{million}$ in Italy for their activities (59). Currently Germany has a moratorium law stating that for any price increase, there will be an 
increase in the mandatory rebate of exactly the same amount as the increase. Effectively, this means that the price paid by statutory heath care funds for ambulatory care medicines does not change (114, 115). Legislation is also being introduced in the UK to reduce the price of generic medicines where competition fails to reduce prices and companies are seen to charge the NHS unreasonably high prices (113). The Competition and Markets Authority (CMA) in the UK has also provisionally found that two companies broke the law by agreeing not to compete to supply generic hydrocortisone to the national health service driving up annual costs by GB£2.0million (116). There are also ongoing deliberations in Europe regarding concerns with appreciable price increases for generics and whether this breaks EU competition rules $(60,117)$. In addition, we may see countries combining to form regional co-operations between Member States to further reduce prices where there are concerns with unjustified price rises building on current consortia (118-120). However, this has to be balanced against issues of future profitability and potential drug shortages with for instance only 75 melphalan tablets dispensed in ambulatory care in Scotland during the study period (SM personal communication), and just with just 11 boxes of generic melphalan dispensed in Serbia in 2015.

\section{Discussion}

We believe this is the first study to comprehensively research the situation regarding the pricing of oral generic cancer medicines in this high priority disease area. We believe our findings again highlight the differences that are seen in the various approaches to the pricing of generics across Europe (Table 1) and their subsequent influence on the prices of generics and discounts obtained. These considerable differences are in direct contrast with the more limited differences in prices for onpatent medicines across Europe, especially high cost ones (121), although these can still be considerable (122).

Prices for generic capecitabine, imatinib, and temozolomide $20 \mathrm{mg}$, were significantly higher when combined among Western European countries as compared with CEE countries. This may reflect greater availability of resources to spend on medicines among Western countries. However, this is not universal as there were no differences in prices between Western European and CEE countries for flutamide or temozolomide $250 \mathrm{mg}$. Alternatively, generics may be available earlier in CEE countries with associated earlier falls in their price as seen with imatinib. As mentioned, generic imatinib in Scotland was already $89.1 \%$ below pre-patent loss prices in March 2018 having only been made available in 2016 (Figure 1). Having said this, there were already some appreciable price reductions for these various molecules and strengths among Western European countries comparing generic prices in 2017 vs. originator prices in 2013 (Table 2 and Figure 3). In addition, no overall difference in the price reductions for these molecules and strengths was found for Western European countries combined versus CEE countries combined.

The picture regarding methotrexate is complicated by the use of this medicine for immunological conditions such as rheumatoid arthritis and psoriasis. This meant that different originator and tablet strengths $(2.5$ or $5 \mathrm{mg})$ were available amongst the European countries making comparisons difficult. In addition, the considerable time that both the originator and generic methotrexate have been available across Europe meant there were limited price reductions in reality between 2017 compared with 2013 among the various European countries. Consequently, no detailed analysis was undertaken with methotrexate.

The price reductions for capecitabine, flutamide, imatinib and temozolomide that have been achieved in practice (Table 2) confirm the findings of Hill et al that the costs of goods for cancer medicines can be very low in reality $(52,53)$. This fuels the debate for greater transparency in the pricing of new medicines for cancer when pharmaceutical companies request premium prices especially where there is limited health gain for their new cancer medicines versus current standards.

In view of our findings, we also believe European health authorities, as well as health authorities from other countries, can use these results to re-assess their pricing approaches for generics, and the subsequent implications for oral generic cancer medicines, given concerns with the increasing costs of medicines to treat patients with cancer and issues of sustainability (28). This is already happening, and may well accelerate, especially if issues of access and sustainability of cancer care continue to be priority issues for all key stakeholder groups. For instance, Austria, Lithuania, and Sweden, have recently introduced measures to further lower the prices they pay for generics and this trend is likely to continue (Table 1). However, this has to be balanced against issues of parallel exports and 
associated drug shortages if the prices of generics become too low $(37,123)$, which is depicted in the unavailability of some oral generic cancer medicines in the countries studied. This will be the subject of ongoing research.

Based on our findings combined with the continual pressure on oncology budgets, we would also likely to see countries increasingly re-assess the prices of on-patent cancer medicines in their country once the comparator medicine used for pricing and reimbursement negotiations loses its patent (124). Such activities will be enhanced by the low prices that have been achieved for oral cancer medicines once their patent is lost (Tables 2 and 3), which will continue.

Encouragingly, unlike the situation with pregabalin (61), we saw no differences in the pricing approaches for generic cancer medicines versus those for other disease areas despite the emotive nature of cancer, and this will continue. This is essential to maximise savings from the availability of generic cancer medicines once available, with ongoing initiatives across Europe to encourage their use where pertinent. Likely current and future initiatives to enhance the prescribing of oral generic cancer medicines include additional demand-side measures especially among European countries with currently low use of generics versus originators. This could be alongside continued educational initiatives among key stakeholder groups, including patients, where pertinent about the lack of problems with oral generic cancer medicines given there were no concerns with substitution among the European countries surveyed (Table 1).

We are also unlikely to see major changes in pricing approaches once one indication loses its patent. The situation seen in Germany, as well as initiatives to encourage INN prescribing, helps in this regard. These initiatives are essential in oncology given the growing burden of the cost of medicines to treat patients with cancer across Europe combined with the need to continue to provide universal healthcare. Encouraging greater prescribing of generic medicines will be helped by limited or no fears with substituting generic cancer medicines for originators among physicians and pharmacists. This is unlike a limited number of other disease areas including some medicines for patients with epilepsy as well as lithium for patients with certain mental health conditions (67-69).

If companies continue to purchase the patent for old cancer medicines and other products, and relaunch them at considerably higher prices, there is likely to be co-ordinated activities across Europe to try and address this. We are already seeing companies being fined, e.g. Italy, as well as countries instigating measures to reduce any burden from such approaches as seen currently in Germany and the UK. Such punitive actions are likely to grow in the future if this trend continues. However, this has to be balanced against potential availability especially if only small volumes are being used. This will again be the subject of continuing research.

\section{Conclusion}

We have again seen appreciable differences in the regulations surrounding the pricing of generics across Europe, reflected in different reimbursed prices for oral generic cancer medicines. Welcomed from an equity and resource perspective were no differences in the pricing approaches for medicines for cancer as opposed to other disease areas to help maximise savings once generics become available. In addition, the prices of generics, and any difference in the prices of generics in 2017, or price reductions versus 2013 originator prices, did not appear to be influenced by population size. This is also encouraging to maximise savings from the availability of oral generic cancer medicines. The prices of some generics were higher among Western European countries in 2017; however, this could have been influenced by generics being available earlier among CEE countries. There are concerns with some off-patented medicines being re-launched by alternative companies at appreciably higher prices, although there are ongoing steps across Europe to try to address this. These initiatives are likely to grow if this trend continues.

Reassuringly, there are no concerns with substitution of oral generic medicines. In addition, prices were typically similar across indications. Both results are important to maximise savings from generic availability once at least one indication loses its patent.

We have tried to reduce limitations with this study by using senior level personnel for the qualitative research as well as health authority and health insurance company databases for the quantitative research. However, we are aware that we did not use reimbursed prices throughout the countries, 
some prices did not include VAT, and we cannot be sure that the medicines chosen for the research are entirely used for cancer indications. Despite these concerns, we believe the findings of our comprehensive research are robust providing direction not only to key stakeholder groups across Europe but also wider.

\section{Funding and Conflict of interest}

Most of the authors work directly for health authorities or health insurance companies or are advisers to them. Steven Simoens has previously held the EGA Chair "European policy towards generic medicines". All the authors have no other conflicts of interest to declare.

There was no funding for this research and no assistance with the write-up.

\section{References}

1. Kelly RJ, Smith TJ. Delivering maximum clinical benefit at an affordable price: engaging stakeholders in cancer care. The Lancet Oncology. 2014;15(3):e112-8.

2. Howard DH, Bach P, Berndt ER, Conti RM. Pricing in the Market for Anticancer Drugs. Journal of Economic Perspectives. 2015;29(1):139-62.

3. Godman B, Wild C, Haycox A. Patent expiry and costs for anti-cancer medicines for clinical use. Generics and Biosimilars Initiative Journal 2017;6(3):105-6.

4. Prasad V, Wang R, Afifi SH, Mailankody S. The Rising Price of Cancer Drugs-A New Old Problem? JAMA oncology. 2016.

5. Kantarjian HM, Fojo T, Mathisen M, Zwelling LA. Cancer drugs in the United States: Justum Pretium--the just price. Journal of clinical oncology. 2013;31(28):3600-4.

6. $\quad$ Cohen D. Cancer drugs: high price, uncertain value. BMJ. 2017;359:j4543.

7. Grössmann N, Wild C. Between January 2009 and April 2016, 134 novel anticancer therapies were approved: what is the level of knowledge concerning the clinical benefit at the time of approval? ESMO Open. 2017;1:e000125. doi:10.1136/ esmoopen-2016-000125.

8. Bach PB, Saltz LB. Raising the Dose and Raising the Cost: The Case of Pembrolizumab in Lung Cancer. Journal of the National Cancer Institute. 2017;109(11).

9. Godman B, Oortwijn W, de Waure C, Mosca I, Puggina A, Specchia ML et al. Links between Pharmaceutical R\&D Models and Access to Affordable Medicines. A Study for the ENVI COMMITTEE. Available at URL:

http://www.europarl.europa.eu/RegData/etudes/STUD/2016/587321/IPOL STU(2016)587321 EN.pdf 10. Dusetzina SB. Drug Pricing Trends for Orally Administered Anticancer Medications Reimbursed by Commercial Health Plans, 2000-2014. JAMA oncology. 2016;2(7):960-1.

11. Gordon N, Stemmer SM, Greenberg D, Goldstein DA. Trajectories of Injectable Cancer Drug Costs After Launch in the United States. Journal of clinical oncology. 2017:Jco2016722124.

12. Gyawali B, Sullivan R. Economics of Cancer Medicines: For Whose Benefit? The New bioethics : a multidisciplinary journal of biotechnology and the body. 2017;23(1):95-104.

13. Chalkidou K, Marquez P, Dhillon PK, Teerawattananon Y, Anothaisintawee T, Gadelha CA, et al. Evidence-informed frameworks for cost-effective cancer care and prevention in low, middle, and high-income countries. The Lancet Oncology. 2014;15(3):e119-31.

14. Wilking N, Lopes G, Meier K, Simoens S, van Harten W, Vulto A. Can we Continue to Afford Access to Cancer Treatment? European Oncology \& Haematology,. 2017;13(2):114-9.

15. ACS Chemical - Neurosciences. New 2016 Data and Statistics for Global Pharmaceutical Products and Projections through 2017. Available at URL:

https://pubs.acs.org/doi/pdfplus/10.1021/acschemneuro.7b00253.

16. Allied Market Research. Oncology/Cancer Drugs Market by Therapeutic Modalities (Chemotherapy, Targeted Therapy, Immunotherapy, Hormonal), Cancer Types (Blood, Breast, Gastrointestinal , Prostate, Skin, Respiratory/Lung Cancer) - Global Opportunity Analysis and Industry Forecast, 2013 - 2020. Available at URL: https://www.alliedmarketresearch.com/oncology-cancerdrugs-market?oncology-cancer-drugs-market

17. IMS Institute for Healthcare Informatics. Global Oncology Trend Report. A Review of 2015 and Outlook to 2020. June 2016. Available at URL:

https://www.scribd.com/document/323179495/IMSH-Institute-Global-Oncology-Trend-2015-2020Report. 
18. Simoens S, van Harten W, Lopes G, Vulto A, Meier K, Wilking N. What Happens when the Cost of Cancer Care Becomes Unsustainable. European Oncology \& Haematology. 2017;13(2):10813.

19. Tefferi A, Kantarjian H, Rajkumar SV, Baker LH, Abkowitz JL, Adamson JW, et al. In Support of a Patient-Driven Initiative and Petition to Lower the High Price of Cancer Drugs. Mayo Clin Proc. 2015;90(8):996-1000.

20. Sarwar MR, Iftikhar S, Saqib A. Availability of anticancer medicines in public and private sectors, and their affordability by low, middle and high-income class patients in Pakistan. BMC cancer. 2018;18(1):14.

21. Atieno OM, Opanga S, Martin A, Kurdi A, Godman B. Pilot study assessing the direct medical cost of treating patients with cancer in Kenya; findings and implications for the future. Journal of medical economics. 2018;21(9):878-87.

22. Jakupi A, Godman B, Martin A, Haycox A, Baholli I. Utilization and Expenditure of Anti-cancer Medicines in Kosovo: Findings and Implications. PharmacoEconomics - open. 2018.

23. Ghinea H, Kerridge I, Lipworth W. If we don't talk about value, cancer drugs will become terminal for health systems http://theconversation.com/if-we-dont-talk-about-value-cancer-drugs-willbecome-terminal-for-health-systems-44072

24. Prasad V, De Jesus K, Mailankody S. The high price of anticancer drugs: origins, implications, barriers, solutions. Nature reviews Clinical oncology. 2017;14(6):381-90.

25. Goldstein DA, Clark J, Tu Y, Zhang J, Fang F, Goldstein R, et al. A global comparison of the cost of patented cancer drugs in relation to global differences in wealth. Oncotarget.

$2017 ; 8(42): 71548-55$.

26. Hoen E't. ACCESS TO CANCER TREATMENT. A study of medicine pricing issues with recommendations for improving access to cancer medication. Available at URL:http://apps.who.int/medicinedocs/documents/s21758en/s21758en.pdf.

27. Haycox A. Why Cancer? PharmacoEconomics. 2016;34(7):625-7.

28. Yang YT, Nagai S, Chen BK, Qureshi ZP, Lebby AA, Kessler S, et al. Generic oncology drugs: are they all safe? The Lancet Oncology. 2016;17(11):e493-e501.

29. Godman B, Wettermark B, van Woerkom M, Fraeyman J, Alvarez-Madrazo S, Berg C, et al. Multiple policies to enhance prescribing efficiency for established medicines in Europe with a particular focus on demand-side measures: findings and future implications. Frontiers in pharmacology. 2014;5:106.

30. Godman B, Shrank W, Andersen M, Berg C, Bishop I, Burkhardt T, et al. Comparing policies to enhance prescribing efficiency in Europe through increasing generic utilization: changes seen and global implications. Expert review of pharmacoeconomics \& outcomes research. 2010;10(6):707-22. 31. Garuoliene K, Godman B, Gulbinovic J, Wettermark B, Haycox A. European countries with small populations can obtain low prices for drugs: Lithuania as a case history. Expert review of pharmacoeconomics \& outcomes research. 2011;11(3):343-9.

32. Dylst $P$, Vulto A, Simoens S. Demand-side policies to encourage the use of generic medicines: an overview. Expert review of pharmacoeconomics \& outcomes research. 2013;13(1):5972.

33. Dylst P, Vulto A, Godman B, Simoens S. Generic medicines: solutions for a sustainable drug market? Applied health economics and health policy. 2013;11(5):437-43.

34. Babar ZU, Kan SW, Scahill S. Interventions promoting the acceptance and uptake of generic medicines: a narrative review of the literature. Health policy. 2014;117(3):285-96.

35. Moe-Byrne T, Chambers D, Harden M, McDaid C. Behaviour change interventions to promote prescribing of generic drugs: a rapid evidence synthesis and systematic review. BMJ open. 2014;4(5):e004623.

36. Kaplan WA, Ritz LS, Vitello M, Wirtz VJ. Policies to promote use of generic medicines in low and middle income countries: a review of published literature, 2000-2010. Health policy.

2012;106(3):211-24.

37. WOUTERS OJ, Kanavos P, McKEE M. Comparing Generic Drug Markets in Europe and the United States: Prices, Volumes, and Spending. The Milbank Quarterly. 2017;95(3):554-601.

38. Bucek Psenkova M, Visnansky M, Mackovicova S, Tomek D. Drug Policy in Slovakia. Value in health regional issues. 2017;13:44-9.

39. Kesselheim AS, Misono AS, Lee JL, Stedman MR, Brookhart MA, Choudhry NK, et al. Clinical equivalence of generic and brand-name drugs used in cardiovascular disease: a systematic review and meta-analysis. Jama. 2008;300(21):2514-26. 
40. Lessing C, Ashton T, Davis PB. The impact on health outcome measures of switching to generic medicines consequent to reference pricing: the case of olanzapine in New Zealand. Journal of primary health care. 2015;7(2):94-101.

41. Veronin M. Should we have concerns with generic versus brand antimicrobial drugs? A review of issues. JPHSR 2011;2:135-50.

42. Paton C. Generic clozapine: outcomes after switching formulations. The British journal of psychiatry. 2006;189:184-5.

43. Corrao G, Soranna D, Arfe A, Casula M, Tragni E, Merlino L, et al. Are generic and brandname statins clinically equivalent? Evidence from a real data-base. European journal of internal medicine. 2014;25(8):745-50.

44. Corrao G, Soranna D, Merlino L, Mancia G. Similarity between generic and brand-name antihypertensive drugs for primary prevention of cardiovascular disease: evidence from a large population-based study. European journal of clinical investigation. 2014;44(10):933-9.

45. Mathews V. Generic imatinib: the real-deal or just a deal? Leukemia \& lymphoma. 2014;55(12):2678-80.

46. Malhotra H, Sharma P, Bhargava S, Rathore OS, Malhotra B, Kumar M. Correlation of plasma trough levels of imatinib with molecular response in patients with chronic myeloid leukemia. Leukemia \& lymphoma. 2014;55(11):2614-9.

47. de Lemos M, Kletas V. GENERIC IMATINIB: REVIEW OF THE LITERATURE ON CLINICAL EFFICACY. Available at URL:

http://www.capho.org/sites/default/files/nops/Generic\%20lmatinib\%20Review\%20of\%20the\%20Literat ure $\% 20$ on $\% 20$ Clinical $\% 20$ Efficacy $\% 20-\% 20$ Mario $\% 20$ de $\% 20$ Lemos.pdf.

48. Dylst $P$, Vulto A, Simoens S. Societal value of generic medicines beyond cost-saving through reduced prices. Expert review of pharmacoeconomics \& outcomes research. 2015;15(4):701-11.

49. Woerkom M, Piepenbrink H, Godman B, Metz J, Campbell S, Bennie M, et al. Ongoing measures to enhance the efficiency of prescribing of proton pump inhibitors and statins in The Netherlands: influence and future implications. Journal of comparative effectiveness research. 2012;1(6):527-38.

50. Simoens S. International comparison of generic medicine prices. Current medical research and opinion. 2007;23(11):2647-54.

51. Wouters OJ, Kanavos PG. A comparison of generic drug prices in seven European countries: a methodological analysis. BMC health services research. 2017;17(1):242.

52. Hill A, Gotham D, Fortunak J, Meldrum J, Erbacher I, Martin M, et al. Target prices for mass production of tyrosine kinase inhibitors for global cancer treatment. BMJ open. 2016;6(1):e009586. 53. Hill A, Redd C, Gotham D, Erbacher I, Meldrum J, Harada R. Estimated generic prices of cancer medicines deemed cost-ineffective in England: a cost estimation analysis. BMJ open. 2017;7(1):e011965.

54. Chen CT, Kesselheim AS. Journey of Generic Imatinib: A Case Study in Oncology Drug Pricing. Journal of oncology practice. 2017;13(6):352-5.

55. Barber M, Gotham D, Hill A. Potential price reductions for cancer medicines on the WHO Essential Medicines List. Avaiable at URL:

http://apps.who.int/medicinedocs/documents/s23154en/s23154en.pdf.

56. Guan X, Tian Y, Ross-Degnan D, Man C, Shi L. Interrupted time-series analysis of the impact of generic market entry of antineoplastic products in China. BMJ open. 2018;8(7):e022328.

57. Matusewicz W, Godman B, Pedersen HB, Furst J, Gulbinovic J, Mack A, et al. Improving the managed introduction of new medicines: sharing experiences to aid authorities across Europe. Expert review of pharmacoeconomics \& outcomes research. 2015;15(5):755-8.

58. Hawkes N. Drug company Aspen faces probe over hiking generic prices. BMJ.

2017;357:j2417.

59. Kahn T. Aspen loses Italy appeal over cancer drug prices. Available at URL:

https://www.businesslive.co.za/bd/companies/healthcare/2017-06-15-aspen-loses-italy-appeal-overcancer-drug-prices/.

60. Pagliarulo N. EU investigating generic drugmaker over cancer drug price hikes. Available at URL: https://www.biopharmadive.com/news/aspen-pharma-antitrust-generic-drugs-EC-europeinvestigation/442722/.

61. Godman B, Wilcock M, Martin A, Bryson S, Baumgärtel C, Bochenek T, de Bruyn M. Generic pregabalin; current situation and implications for health authorities, generics and biosimilars

manufacturers in the future. GaBI Journal. 2015;4(3):125-35. 
62. McLaughlin M, Kotis D, Thomson K, Harrison M, Fennessy G, Postelnick M, et al. Empty shelves, full of frustration: consequences of drug shortages and the need for action. Hospital pharmacy. 2013;48(8):617-8.

63. Putrik P, Ramiro S, Kvien TK, Sokka T, Pavlova M, Uhlig T, et al. Inequities in access to biologic and synthetic DMARDs across 46 European countries. Annals of the rheumatic diseases. 2014;73(1):198-206.

64. Kostic M, Djakovic L, Sujic R, Godman B, Jankovic SM. Inflammatory Bowel Diseases (Crohn s Disease and Ulcerative Colitis): Cost of Treatment in Serbia and the Implications. Applied health economics and health policy. 2017;15(1):85-93.

65. Cameron A, Mantel-Teeuwisse AK, Leufkens HG, Laing RO. Switching from originator brand medicines to generic equivalents in selected developing countries: how much could be saved? Value in health : the journal of the International Society for Pharmacoeconomics and Outcomes Research. 2012;15(5):664-73.

66. Wild C, Grossmann N, Bonanno PV, Bucsics A, Furst J, Garuoliene K, et al. Utilisation of the ESMO-MCBS in practice of HTA. Annals of oncology. 2016;27(11):2134-6.

67. Duerden MG, Hughes DA. Generic and therapeutic substitutions in the UK: are they a good thing? British journal of clinical pharmacology. 2010;70(3):335-41.

68. Ferner RE, Lenney W, Marriott JF. Controversy over generic substitution. BMJ. 2010;340:c2548.

69. MHRA. Antiepileptic drugs: updated advice on switching between different manufacturers' products. 2017. Available from URL: https://www.gov.uk/drug-safety-update/antiepileptic-drugsupdated-advice-on-switching-between-different-manufacturers-products\#chm-review-and-update. 70. Godman B, Shrank W, Andersen M, Berg C, Bishop I, Burkhardt T, et al. Policies to enhance prescribing efficiency in europe: findings and future implications. Frontiers in pharmacology. 2010;1:141.

71. McKee M, Stuckler D, Martin-Moreno JM. Protecting health in hard times. BMJ. 2010;341:c5308.

72. Markovic-Pekovic V, Skrbic R, Godman B, Gustafsson LL. Ongoing initiatives in the Republic of Srpska to enhance prescribing efficiency: influence and future directions. Expert review of pharmacoeconomics \& outcomes research. 2012;12(5):661-71.

73. Moorkens E, Vulto AG, Huys I, Dylst P, Godman B, Keuerleber S, et al. Policies for biosimilar uptake in Europe: An overview. PloS one. 2017;12(12):e0190147.

74. Baumgärtel C, Godman B, Malmström R, Andersen M, Abuelkhair M, Abdu S et al. What lessons can be learned from the launch of generic clopidogrel? GaBI Journal. 2012;1(2):58-68.

75. OECD. OECD Glossary of Statistical Terms. Available at URL: http://www.oecd-

ilibrary.org/docserver/download/3008121e.pdf?expires=1521443673\&id=id\&accname=guest\&checksu $\mathrm{m}=$ EDB68C374A8FE629D5A2C1FAFB0AEB6C.

76. Coma A, Zara C, Godman B, Agusti A, Diogene E, Wettermark B, et al. Policies to enhance the efficiency of prescribing in the Spanish Catalan region: impact and future direction. Expert review of pharmacoeconomics \& outcomes research. 2009;9(6):569-81.

77. Kanavos P. Generic policies: rhetoric vs. reality. Euro Observer. 2008; 10(2): 1-6. Available at URL: http://apps.who.int/medicinedocs/documents/s20146en/s20146en.pdf.

78. Website. Piperska 2017. Available from URL: http://www.piperska.org/.

79. Garattini S, Bertele V, Godman B, Haycox A, Wettermark B, Gustafsson LL. Enhancing the rational use of new medicines across European health care systems. European journal of clinical pharmacology. 2008;64(12):1137-8.

80. Moon JC, Godman B, Petzold M, Alvarez-Madrazo S, Bennett K, Bishop I, et al. Different initiatives across Europe to enhance losartan utilization post generics: impact and implications.

Frontiers in pharmacology. 2014;5:219.

81. Godman B, Petzold M, Bennett K, Bennie M, Bucsics A, Finlayson AE, et al. Can authorities appreciably enhance the prescribing of oral generic risperidone to conserve resources? Findings from across Europe and their implications. BMC medicine. 2014;12:98.

82. Voncina L, Strizrep T, Godman B, Bennie M, Bishop I, Campbell S, et al. Influence of demand-side measures to enhance renin-angiotensin prescribing efficiency in Europe: implications for the future. Expert review of pharmacoeconomics \& outcomes research. 2011;11(4):469-79.

83. Ferrario A, Arāja D, Bochenek T, Čatić T, Dankó D, Dimitrova M, et al. The Implementation of Managed Entry Agreements in Central and Eastern Europe: Findings and Implications.

PharmacoEconomics. 2017;35(12):1271-85. 
84. Godman B, Shrank W, Wettermark B, Andersen M, Bishop I, Burkhardt T, et al. Use of Generics-A Critical Cost Containment Measure for All Healthcare Professionals in Europe? Pharmaceuticals. 2010;3(8):2470-94.

85. Godman B, Bucsics A, Burkhardt T, Piessnegger J, Schmitzer M, Barbui C, et al. Potential to enhance the prescribing of generic drugs in patients with mental health problems in austria; implications for the future. Frontiers in pharmacology. 2012;3:198.

86. Simoens S. A review of generic medicine pricing in Europe. Generics and Biosimilar Journal. 2012;1(1):8-12.

87. Leopold C, Vogler S, Mantel-Teeuwisse AK, de Joncheere K, Leufkens HG, Laing R. Differences in external price referencing in Europe: a descriptive overview. Health policy.

2012;104(1):50-60.

88. Leporowski A, Godman B, Kurdi A, MacBride-Stewart S, Ryan M, Hurding S, et al. Ongoing activities to optimize the quality and efficiency of lipid-lowering agents in the Scottish national health service: influence and implications. Expert review of pharmacoeconomics \& outcomes research. 2018;18(6):655-66.

89. WHO. WHO Collaborating Centre for Drug Statistics Methodology. ATC/ DDD Index. Available at URL: https://www.whocc.no/

90. Venkatesan S, Lamfers M, Leenstra S, Vulto AG. Overview of the patent expiry of (non)tyrosine kinase inhibitors approved for clinical use in the EU and the US. GaBI Journal. 2017;6(2):8996.

91. Clopes A, Gasol M, Cajal R, Segu L, Crespo R, Mora R, et al. Financial consequences of a payment-by-results scheme in Catalonia: gefitinib in advanced EGFR-mutation positive non-small-cell lung cancer. Journal of medical economics. 2017;20(1):1-7.

92. Dylst $P$, Simoens $S$. Does the market share of generic medicines influence the price level?: a European analysis. PharmacoEconomics. 2011;29(10):875-82.

93. BBC News - Health. Cancer drugs price rise 'costing NHS millions'. Available at URL: http://www.bbc.co.uk/news/health-38769625.

94. Vella O. Further reductions in medicine prices. Available at URL:

https://www.timesofmalta.com/articles/view/20170115/consumer-affairs/Further-reductions-inmedicine-prices.636591.

95. Petrova G. PRICING AND REIMBURSEMENT OF MEDICINES IN CENTRAL AND EAST EUROPEAN COUNTRIES2014. 4311-28 p.

96. Kawalec P, Stawowczyk E, Tesar T, Skoupa J, Turcu-Stiolica A, Dimitrova M, et al. Pricing and Reimbursement of Biosimilars in Central and Eastern European Countries. Frontiers in pharmacology. 2017;8:288.

97. Baltic Statistics on Medicines 2010 - 2012. Available at URL:

file://C:/Users/mail/Desktop/My\%20documents/Ongoing\%20papers/Expert\%20Review\%20generic\% 20cancer\%20medicines/baltic_statistics_on_medicines_2010_2012.pdf.

98. Marcheva M T-KL, Petrova G. PRICING AND REIMBURSEMENT OF MEDICINES IN CENTRAL AND EAST EUROPEAN COUNTRIES. World Journal of Pharmacy and Pharmaceutical Sciences. 2013;2(6):4311-28.

99. Festøy H, Aanes T, Ognøy AE. PPRI Pharma Profile Norway June 2015. Available at URL: http://whocc.goeg.at/Literaturliste/Dokumente/CountryInformationReports/PPRI Pharma Profile Nor way 20150626 final.pdf.

100. Godman B, Sakshaug S, Berg C, Wettermark B, Haycox A. Combination of prescribing restrictions and policies to engineer low prices to reduce reimbursement costs. Expert review of pharmacoeconomics \& outcomes research. 2011;11(1):121-9.

101. Kalaba M, Godman B, Vuksanovic A, Bennie M, Malmstrom RE. Possible ways to enhance renin-angiotensin prescribing efficiency: Republic of Serbia as a case history? Journal of comparative effectiveness research. 2012;1(6):539-49.

102. Vogler S, Zimmermann N, Gombocz M, Mörtenhuber S, Skala R, Lichtenecker J et al. Short PPRI Pharma Profile Austria. January 2018. Available at URL:

http://whocc.goeg.at/Literaturliste/Dokumente/CountrylnformationReports/Short PPRI Pharma Profil e AT 2017 final neu.pdf

103. Bucsics A, Godman B, Burkhardt T, Schmitzer M, Malmstrom RE. Influence of lifting prescribing restrictions for losartan on subsequent sartan utilization patterns in Austria: implications for other countries. Expert review of pharmacoeconomics \& outcomes research. 2012;12(6):809-19. 
104. Godman B, Abuelkhair M, Vitry A, Abdu S, Bennie M, Bishop I et al. Payers endorse generics to enhance prescribing efficiency: impact and future implications, a case history approach.

2012;1(2):69-83.

105. Pontén J, Rönnholm G, Skiöld P. PPRI Pharma Profile Sweden. April 2017. Available at URL: http://whocc.goeg.at/Literaturliste/Dokumente/CountrylnformationReports/PPRI Pharma Profile Swe den 2017.pdf.

106. Godman B, Persson M, Miranda J, Skiold P, Wettermark B, Barbui C, et al. Changes in the utilization of venlafaxine after the introduction of generics in Sweden. Applied health economics and health policy. 2013;11(4):383-93.

107. GABI Journal. The Greek problem of generics pricing. Available at URL:

http://www.gabionline.net/Generics/Research/The-Greek-problem-of-generics-pricing.

108. Vogler $\mathrm{S}$. The impact of pharmaceutical pricing and reimbursement policies on generics uptake: implementation of policy options on generics in 29 European countries-an overview. Generics and Biosimilar Journal. 2012;1(2):93-100.

109. Dylst $P$, Vulto A, Simoens S. Analysis of the Italian generic medicines retail market: recommendations to enhance long-term sustainability. Expert review of pharmacoeconomics \& outcomes research. 2015;15(1):33-42.

110. Godman B, Bishop I, Finlayson AE, Campbell S, Kwon HY, Bennie M. Reforms and initiatives in Scotland in recent years to encourage the prescribing of generic drugs, their influence and implications for other countries. Expert review of pharmacoeconomics \& outcomes research. 2013;13(4):469-82.

111. McGinn D, Godman B, Lonsdale J, Way R, Wettermark B, Haycox A. Initiatives to enhance the quality and efficiency of statin and PPI prescribing in the UK: impact and implications. Expert review of pharmacoeconomics \& outcomes research. 2010;10(1):73-85.

112. Bennie M, Godman B, Bishop I, Campbell S. Multiple initiatives continue to enhance the prescribing efficiency for the proton pump inhibitors and statins in Scotland. Expert review of pharmacoeconomics \& outcomes research. 2012;12(1):125-30.

113. UK Departemnt of Health and Social Care. Health Service Medical Supplies (Costs) Bill factsheet. Updated 8 November 2016. Available at URL:

https://www.gov.uk/government/publications/health-service-medical-supplies-costs/health-servicemedical-supplies-costs-bill-factsheet.

114. Bundesministerium für Gesundheit. Preismoratorium für Arzneimittel. Available at URL: https://www.bundesgesundheitsministerium.de/themen/krankenversicherung/arzneimittelversorgung/p reismoratorium.html.

115. Bundesministerium für Gesundheit. Sozialgesetzbuch (SGB) Fünftes Buch (V) - Gesetzliche Krankenversicherung - (Artikel 1 des Gesetzes v. 20. Dezember 1988, BGBI. I S. 2477). § 130a

Rabatte der pharmazeutischen Unternehmer. Available at URL: https://www.gesetze-iminternet.de/sgb 5/ 130a.html.

116. UK Government. Pharma firms accused of illegal agreements over life-saving drug. 28

February 2019. Available at URL: https://www.gov.uk/government/news/pharma-firms-accused-of-

illegal-agreements-over-life-saving-drug.

117. European Commission. Antitrust: Commission opens formal investigation into Aspen

Pharma's pricing practices for cancer medicines. 2017. Available at URL:

file:///C:/Users/mail/Downloads/IP-17-1323_EN.pdf.

118. Press Release. Ireland to open negotiations with Belgium, the Netherlands, Luxembourg and Austria on drug pricing and supply - Minister Harris. Available at URL: http://health.gov.ie/blog/pressrelease/ireland-to-open-negotiations-with-belgium-the-netherlands-luxembourg-and-austria-on-drugpricing-and-supply-minister-harris/.

119. European Observatory. How can voluntary cross-border collaboration in public procurement improve access to health technologies in Europe? Available at URL:

http://www.euro.who.int/ data/assets/pdf file/0009/331992/PB21.pdf?ua=1.

120. Ferrario A, Humbert T, Kanavos P, Pedersen HB. Strategic procurement and international collaboration to improve access to medicines. Bulletin of the World Health Organization.

2017;95(10):720-2.

121. Vogler S, Zimmermann N, Babar ZU. Price comparison of high-cost originator medicines in European countries. Expert review of pharmacoeconomics \& outcomes research. 2017;17(2):221-30.

122. Vogler S, Kilpatrick K, Babar ZU. Analysis of Medicine Prices in New Zealand and 16

European Countries. Value in health. 2015;18(4):484-92. 
123. Bochenek T, Abilova V, Alkan A, Asanin B, de Miguel Beriain I, Besovic Z, et al. Systemic Measures and Legislative and Organizational Frameworks Aimed at Preventing or Mitigating Drug Shortages in 28 European and Western Asian Countries. Frontiers in pharmacology. 2017;8:942. 124. Godman B, Bucsics A, Vella Bonanno P, Oortwijn W, Rothe CC, Ferrario A, et al. Barriers for Access to New Medicines: Searching for the Balance Between Rising Costs and Limited Budgets. Front Public Health. 2018;6:328. 


\section{Appendix}

Table 1A - Currency conversion (where used)

\begin{tabular}{|c|c|c|c|c|c|c|}
\hline Country & 2013 & 2014 & 2015 & 2016 & 2017 & Website/ Source \\
\hline $\begin{array}{l}\text { Bulgaria } \\
1 \mathrm{BGN}\end{array}$ & $€ 0.51$ & $€ 0.51$ & $€ 0.51$ & $€ 0.51$ & $€ 0.51$ & \\
\hline $\begin{array}{l}\text { Latvia } \\
1 \text { LATS }\end{array}$ & $€ 0.703$ & & & & & Bank of Latvia. Euros introduced from 2014 \\
\hline $\begin{array}{l}\text { Norway - } \\
€ 1\end{array}$ & $\begin{array}{l}8.383 \\
\text { NK }\end{array}$ & $\begin{array}{l}9.037 \\
\text { NK }\end{array}$ & $\begin{array}{l}9.619 \\
\text { NK }\end{array}$ & $\begin{array}{l}9.086 \\
\text { NK }\end{array}$ & $\begin{array}{l}9.84 \\
\text { NK }\end{array}$ & $\begin{array}{l}\text { https://www.norges- } \\
\text { bank.no/en/statistics/exchange_rates/ }\end{array}$ \\
\hline $\begin{array}{l}\text { Poland - } \\
€ 1\end{array}$ & $\begin{array}{l}4.176 \\
\text { PLN }\end{array}$ & $\begin{array}{l}4.223 \\
\text { PLN }\end{array}$ & $\begin{array}{l}4.291 \\
\text { PLN }\end{array}$ & $\begin{array}{l}4.437 \\
\text { PLN }\end{array}$ & $\begin{array}{l}4.202 \\
\text { PLN }\end{array}$ & http://www.nbp.pl/homen.aspx?f=/kursy/kursyen.htm \\
\hline $\begin{array}{l}\text { Republic } \\
\text { of } \\
\text { Srpska - } \\
€ 1\end{array}$ & $\begin{array}{l}1.955 \\
\text { BAM }\end{array}$ & $\begin{array}{l}1.955 \\
\text { BAM }\end{array}$ & $\begin{array}{l}1.955 \\
\text { BAM }\end{array}$ & $\begin{array}{l}1.955 \\
\text { BAM }\end{array}$ & $\begin{array}{l}1.955 \\
\text { BAM }\end{array}$ & $\begin{array}{l}\text { Central Bank of Bosnia and Herzegovina } \\
\text { https://www.cbbh.ba/CurrencyExchange }\end{array}$ \\
\hline $\begin{array}{l}\text { Serbia - } \\
€ 1\end{array}$ & NA & NA & $\begin{array}{l}122.03 \\
\text { RSD }\end{array}$ & $\begin{array}{l}123.94 \\
\text { RSD }\end{array}$ & $\begin{array}{l}119.49 \\
\text { RSD }\end{array}$ & $\begin{array}{l}\text { http://www.nbs.rs/export/sites/default/internet/ } \\
\text { english/scripts/kl_srednji.html }\end{array}$ \\
\hline $\begin{array}{l}\text { Romania } \\
-€ 1\end{array}$ & $\begin{array}{l}4.42 \\
\text { LEU }\end{array}$ & $\begin{array}{l}4.45 \\
\text { LEU }\end{array}$ & $\begin{array}{l}4.45 \\
\text { LEU }\end{array}$ & $\begin{array}{l}4.49 \\
\text { LEU }\end{array}$ & $\begin{array}{l}4.57 \\
\text { LEU }\end{array}$ & http://www.bnr.ro/Exchange-Rates--3727.aspx \\
\hline *Sweden & $\begin{array}{l}8.96 \\
\text { SEK }\end{array}$ & $\begin{array}{l}9.51 \\
\text { SEK }\end{array}$ & $\begin{array}{l}9.16 \\
\text { SEK }\end{array}$ & $\begin{array}{l}9.58 \\
\text { SEK }\end{array}$ & $\begin{array}{l}9.85 \\
\text { SEK }\end{array}$ & \\
\hline $\begin{array}{l}\text { UK - } \\
1 \mathrm{GBE}\end{array}$ & $€ 1.20$ & $€ 1.28$ & $€ 1.36$ & $€ 1.17$ & $€ 1.13$ & $\begin{array}{l}\text { https://www.poundsterlinglive.com/bank-of-england- } \\
\text { spot/historical-spot-exchange-rates/gbp/GBP-to- } \\
\text { EUR-2016 (similar for each year) }\end{array}$ \\
\hline
\end{tabular}

NB: *Sweden - https://www.riksbank.se/en-gb/statistics/search-interest--exchange-rates/?g130-

SEKEURPMI=on\&from=28\%2F12\%2F2017\&to=29\%2F12\%2F2017\&f=Day\&c=cAverage\&s=Comma

Table 2A - Population sizes among the European countries (millions) for the quantitative research in $\underline{\underline{2017}}$

\begin{tabular}{|c|c|c|c|c|c|c|c|c|}
\hline Country & Number & Category & Country & Number & Category & Country & Number & Category \\
\hline Malta & 0.44 & Small & Norway & 5.3 & Medium & Netherlands & 17 & Large \\
\hline Republic of Srpska & 1.16 & Small & Slovakia & 5.4 & Medium & Romania & 19.64 & Large \\
\hline Cyprus & 1.19 & Small & Serbia & 7.1 & Medium & Poland & 38.42 & Large \\
\hline Estonia & 1.32 & Small & Bulgaria & 7.18 & Medium & Spain & 46.53 & Large \\
\hline Kosovo & 1.883 & Small & Austria & 8.8 & Medium & Italy & 60.51 & Large \\
\hline Latvia & 1.94 & Small & Sweden & 9.95 & Medium & France & 65.02 & Large \\
\hline Slovenia & 2.07 & Small & Greece & 10.84 & Medium & UK & 65.65 & Large \\
\hline Lithuania & 2.81 & Small & Belgium & 11.32 & Medium & & & \\
\hline Albania & 2.87 & Small & & & & & & \\
\hline
\end{tabular}

